Published in: Thin-Walled Structures, 61, 169-179.

DOI: http://dx.doi.org/10.1016/j.tws.2012.03.021

\title{
Slender thin cylindrical shells under unsymmetrical strip loads
}

\section{Adam J. Sadowski ${ }^{1}$ \& J. Michael Rotter ${ }^{2}$}

\begin{abstract}
Modern procedures for the design of shell structures against buckling have their basis in analytical studies of axisymmetric shell geometries under the very simple load cases of uniform compression, external pressure and torsion. Studies of more complex but realistic stress states were based on prebuckling analyses using either membrane theory or linear bending theory because even these involved considerable mathematical complexity. As a result, only limited conclusions for practical design could be drawn and the effects of geometric nonlinearity could not be assessed. With recent advances in computing power and nonlinear finite element programs, it is now possible to undertake nonlinear analyses of complex load patterns that would have been very difficult to do only a decade or so ago.
\end{abstract}

A number of practical load cases lead to a strip of pressure down one meridian, of which the best known ones are probably wind on tanks, eccentric discharge in silos, local thermal differentials, and partial fluid filling of a cylinder. This paper explores some of the rather unexpected stress patterns and modes of buckling that are predicted to develop in thin-walled cylindrical shells under such unsymmetrical strips of normal pressure. The results of a parametric study are presented to show the influence of the circumferential spread of the pressure strip on the structural behaviour. It is shown that the structural response to such loads may be very different, depending on whether the load acts inward or outward, and whether geometric nonlinearity and geometric imperfections are also included in the assessment.

\section{Keywords}

Cylindrical shells, thin-walled shells, shell buckling, unsymmetrical pressures, strip loads, geometric nonlinearity, imperfections.

${ }^{1}$ Research Associate, The University of Edinburgh, UK

${ }^{2}$ Professor of Civil Engineering, The University of Edinburgh, UK 
Published in: Thin-Walled Structures, 61, 169-179.

DOI: http://dx.doi.org/10.1016/j.tws.2012.03.021

\section{Introduction}

Thin shell structures have long been known to be susceptible to buckling failures when compressive stresses develop in their walls. The first studies used analytical treatments of axisymmetric shells under the simplest load cases of uniform compression, external pressure and torsion, and this focus has continued until the present day. Studies of more realistic stress states are inherently more complex and have almost always been based on prebuckling stresses found either using membrane theory or a linear elastic analysis due to the mathematical complexity involved in any more comprehensive treatment. As a result, only limited conclusions for design purposes can be drawn from them and the effects of geometric nonlinearity were difficult to assess. This has led to design provisions (e.g. NASA SP8007, 1968; DIN 18800, 1990; EN 1993-1-6, 2007; ECCS EDR5, 2008) which make very conservative extrapolations from the simple uniform stress cases to deal with these more complex conditions. Recent advances in both computing power and nonlinear finite element programs have made it possible to undertake nonlinear analyses of shells under complex load patterns that were previously very difficult, and consequently to discover very interesting aspects of shell stress states and shell buckling conditions that were not previously recognised.

Several practical load cases may be simplified into a strip of pressure down one meridian of a cylindrical shell. Possibly the best known of these are wind loads on tanks, eccentric discharge of granular solids in silos, local thermal differentials due to sunlight, and partial fluid filling of a horizontal cylinder. This paper explores some of the rather unexpected stress patterns and modes of buckling that are predicted to develop in thin-walled cylindrical shells under such unsymmetrical strips of normal pressure. The results of a parametric study show the effect on the structural behaviour of varying the circumferential spread of an inward or outward pressure strip. It is shown that the structural response to such loads may depend strongly on the inward or outward direction of the pressure, and whether geometric nonlinearity and geometric imperfections are also included in the assessment. Only a few studies have explored the buckling behaviour of a cylindrical shell under unsymmetrical strip loads (Abir and Nardo, 1958; Hoff et al., 1964; Ross et al., 1965; Bushnell and Smith, 1971; Rotter et $a l ., 2011)$ and these have either used only linear bifurcation analyses or dealt with rather different load cases. The literature in this area is therefore very sparse. 
Published in: Thin-Walled Structures, 61, 169-179.

DOI: http://dx.doi.org/10.1016/j.tws.2012.03.021

The most important aspects of the first two of the load patterns named above, eccentric discharge flows in a silo and wind loads on an empty tank, are illustrated qualitatively in Fig. 1. These load cases share the key feature of something like a strip of local inward normal pressure flanked by two strips of local outward normal pressure, acting down the full height of the cylinder. Each may, of course, be accompanied by a superposed uniform internal pressure which is shown in this study to have a substantial influence on the behaviour.

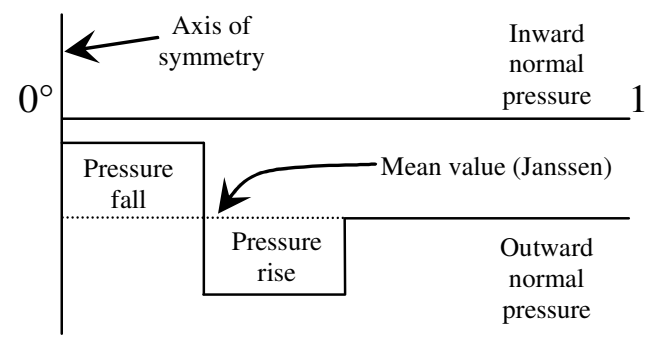

a) Eccentric discharge pressure pattern on a silo (EN 1991-4, 2006)

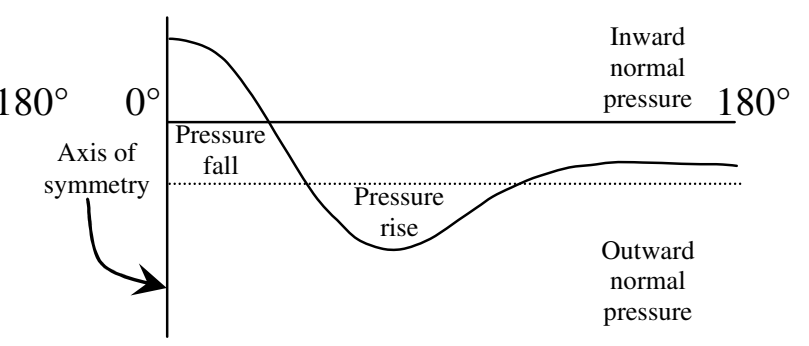

b) Wind pressure distribution on a tank (EN 1993-4-1 Annex C, 2007)

Fig. 1 - Characteristic circumferential form of the normal pressure distribution on a cylindrical silo or tank under unsymmetrical loading

Recent numerical studies of silos under eccentric discharge conditions (Sadowski, 2010; Sadowski \& Rotter, 2010; 2011a, b) (Fig. 1a) have revealed unexpected aspects of the behaviour of cylindrical shells under such loadings. Following the earlier discovery of Rotter $(1986,2001)$, it was confirmed that a slender metal silo subject to a classical Janssen pressure distribution with a superimposed local depression in normal pressure down the entire height of the silo (Nielsen and Kristiansen, 1980; Gale et al., 1986; Chen et al., 1998) may buckle at a significantly lower load factor than one under axisymmetric pressures alone. This finding was backed by experimental evidence (described in Rotter et al., 1989) and many field observations (Rotter, 2011a). As suggested by Gould (1988), the global pattern of axial membrane stresses was found to be analogous to the extreme fibre stresses in a propped cantilever whose cross-section is only that part of the shell that is loaded (Fig. 2). A significantly increased local axial compression is found at the centre of the inward pressure zone, causing premature buckling. Remarkably, geometric nonlinearity proved to have a substantial beneficial effect on the predicted nonlinear buckling strength under this condition. 
Published in: Thin-Walled Structures, 61, 169-179.

DOI: http://dx.doi.org/10.1016/j.tws.2012.03.021

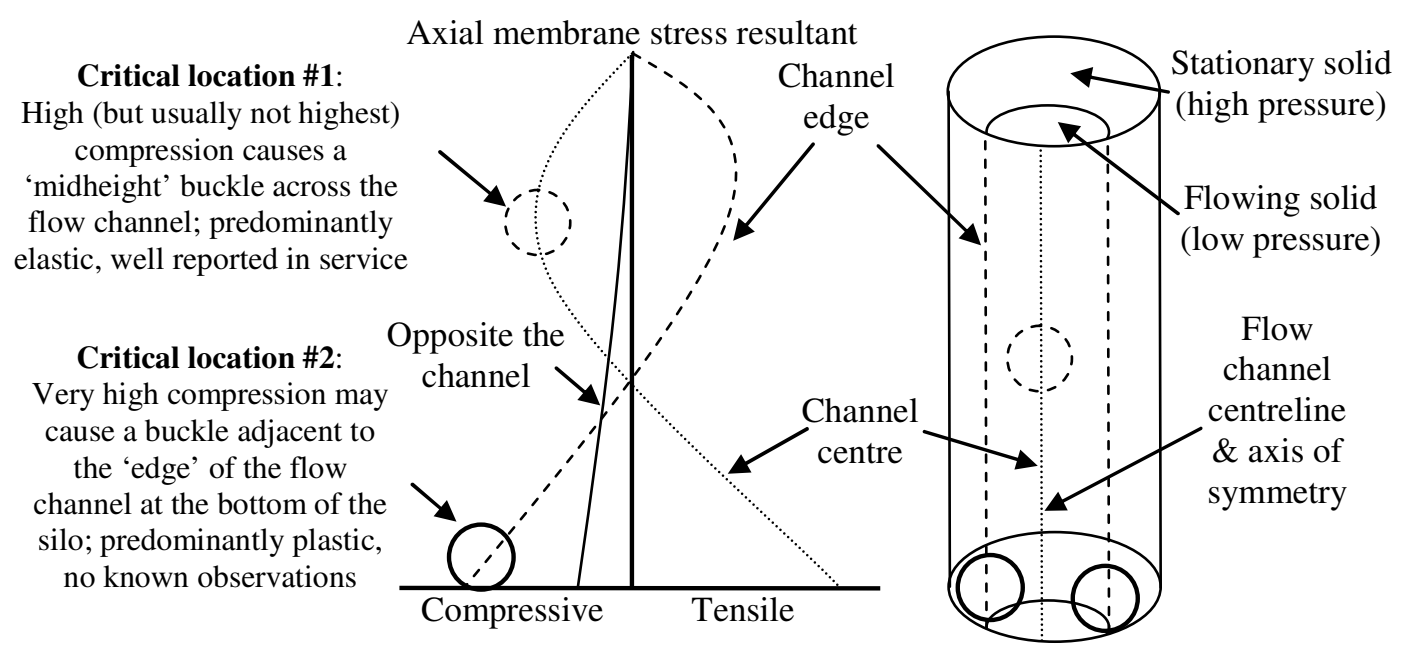

Fig. 2 - Illustration of the characteristic axial membrane stress patterns and buckling modes in slender silos under eccentric discharge pressures

(after Sadowski \& Rotter, 2011b)

In a study of tanks under wind loading (Chen, 2011; Chen \& Rotter, 2012), the linear and nonlinear behaviour of cylindrical storage vessels with a wide range of aspect ratios was investigated under the wind pressure distribution of Annex C of EN 1993-41 (2007). The pattern of axial membrane stresses down the windward generator in a medium slenderness shell found by Greiner (1981) and Greiner and Derler (1995) was confirmed. Amongst many other findings, it was shown that this stress pattern also resembles that of the propped cantilever (Fig. 3) with greatly increased axial compression around the shell mid-height. However, at higher aspect ratios the shell exhibited a global long-wave circumferential compression buckle interacting with a local shear buckle near the base of the shell, which is a markedly different behaviour from that of silos under eccentric discharge. The reasons for this change are illustrated in this paper. Geometric nonlinearity was again found to have a significant effect on the buckling mode, but it is perhaps surprising that it was not found to be beneficial to the buckling strength. The effects of geometric nonlinearity in different shell geometries under unsymmetrical loadings is thus worthy of a more systematic exploration. 

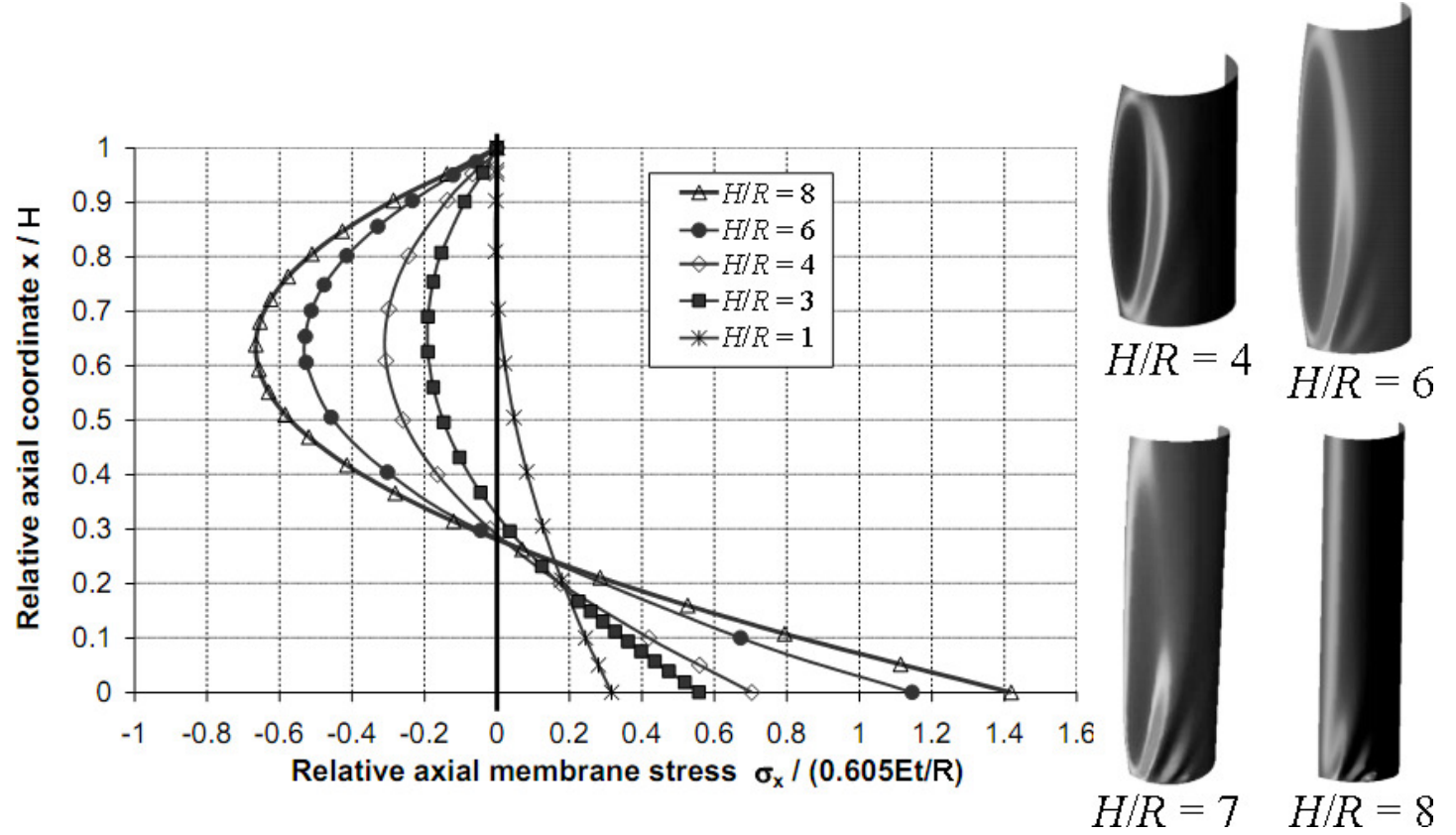

Fig. 3 - Typical axial membrane stress patterns down the windward generator and buckling modes of a medium slender silo under wind loading

(after Chen \& Rotter, 2012)

Finally, it may be noted that the buckling strength assessment process offered in the Eurocode (EN 1993-1-6, 2007) for more complex load cases in shells requires only a linear finite element analysis to be used to determine the linear bifurcation load (LBA) and an estimate of the plastic collapse load (MNA), which are combined to identify the slenderness of the shell. Following these two simple finite element calculations, the LBA-MNA methodology (ECCS EDR5, 2008; Rotter, 2011b) permits the remaining effects that control the strength of the shell to be obtained by estimate from well known and similar load cases. A key aspect of this process is that it must be possible to determine the relative magnitudes of the strength reduction due to imperfections and the strength reduction due to geometric nonlinearity (Rotter, 2011c). To that end, studies of the type undertaken here are vital in the development of the database and understanding of geometrically nonlinear effects in more complex load cases in thin shells. 
Published in: Thin-Walled Structures, 61, 169-179.

DOI: http://dx.doi.org/10.1016/j.tws.2012.03.021

\section{Modelling of a cylindrical shell under three different strip loads down the meridian}

The studies noted above on silos and tanks under eccentric discharge and wind loading suggest that a local decrease in normal pressure (Fig. 1) may have a significant and deleterious effect on the structural stability, and may be more damaging than a local rise in pressure. This paper therefore explores some of the unusual stress patterns and buckling modes that are predicted to occur under unsymmetrical loads. The problem is presented in the general context of a slender cylindrical shell subject to three different configurations of a strip of normal pressure of unit value (1 MPa) acting throughout a meridional band (Fig. 4). These are:

a) an outward pressure strip of unit magnitude,

b) an inward pressure strip of unit magnitude and

c) a strip of unit magnitude inward pressure superimposed on an axisymmetric outward pressure of unit magnitude (the net effect termed here a depression).

The circumferential extent of each strip is defined by a half-angle $\theta_{\mathrm{s}}$ from the axis of longitudinal symmetry. In silos, the normal pressure due to Janssen rapidly tends to a constant value with depth, so a local drop in pressure is close to constant throughout the lower two-thirds of the shell, especially for slender geometries. Wind pressures may similarly be prescribed as invariant with height. Thus a pressure pattern that is invariant with height was chosen here to provide clarity and simplicity. It should be stressed that no additional axial loading of any kind is applied in any of the three cases, and the strip of normal pressure is the only loading present in cases a) and b) above. 


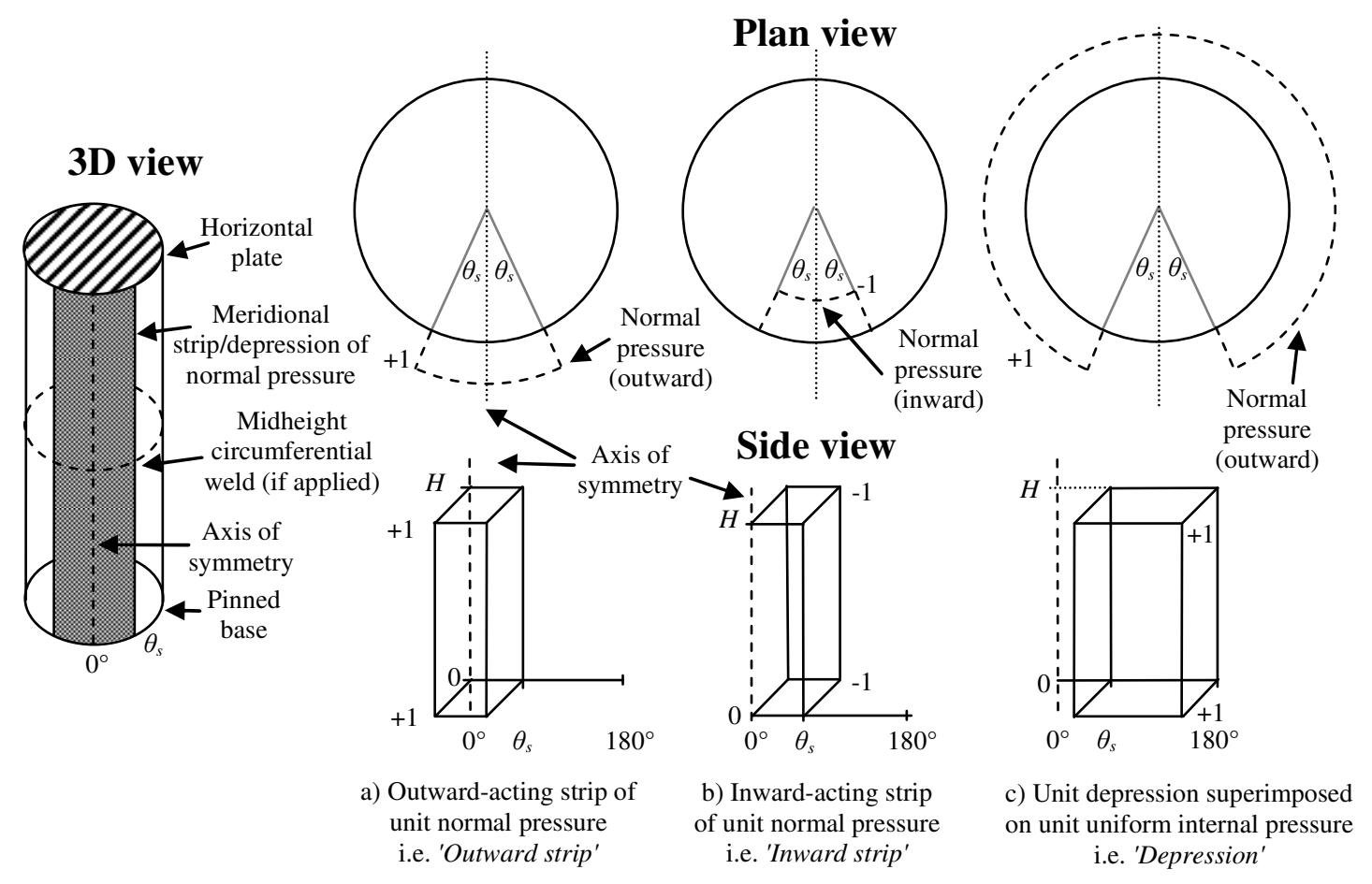

Fig. 4 - Illustration of a typical axial membrane stress patterns and typical buckling mode of a medium-slender silos under wind loading

The cylinder was modelled using the ABAQUS (2009) finite element software with nine-node reduced-integration S9R5 elements, which are recommended for nonlinear elastic stability analyses. The geometry was chosen to ensure an aspect ratio $H / D$ of 2.5 (relatively slender) and a radius to thickness ratio $R / t$ of 2000 (very thin). The base of the cylinder was taken as pinned, while the top of the cylinder was modelled as a thick plate to restrict the out-of-round displacements that may otherwise occur in shells subject to unsymmetrical loads (Calladine, 1983). Only half of the cylinder was analysed with the assumption of a symmetry boundary condition. Values for Young's modulus and Poisson's ratio were taken as $2 \times 10^{5} \mathrm{MPa}$ and 0.3 respectively.

The following computational analyses were performed, as described in the European Standard on Shell Structures EN 1993-1-6 (2007): linear elastic analysis (LA), linear bifurcation analysis (LBA) and geometrically nonlinear elastic analysis (GNA). A set of nonlinear analyses was also performed on imperfect cylinders (GNIA) using a single 'Type A' axisymmetric weld imperfection of Rotter and Teng (1989) placed at midheight. Only elastic analyses were considered. 
Published in: Thin-Walled Structures, 61, 169-179.

DOI: http://dx.doi.org/10.1016/j.tws.2012.03.021

\section{A cylindrical shell under pressure on a narrow strip down the meridian}

\subsection{Global stress patterns at buckling}

Linear and nonlinear stress analyses (LA and GNA) were performed on the cylinder under each of the three pressure patterns on a meridional strip, initially with a relatively narrow half-angle of $\theta_{\mathrm{s}}=15^{\circ}\left(1 / 12^{\text {th }}\right.$ of the circumference). The full strip width was thus $30^{\circ}$. The outcome is presented as a series of distributions at the point of buckling of the most important membrane stress resultants (MSRs) at key locations. Stresses from LA analyses are factored by the lowest eigenvalue from an LBA analysis, while stresses from GNA analyses are those at the critical bifurcation point. The stress resultants are each made dimensionless by their respective critical values for uniform stress buckling (Eqs 1 to 3), as given in EN 1993-1-6 Annex D. These indicate the magnitude of each stress resultant (SR) relative to a critical measure.

Critical axial buckling MSR: $N_{x, c r}=t \sigma_{x, c r}=0.605 E t^{2} R^{-1}$

Critical circumferential buckling MSR: $N_{\theta, c r}=t \sigma_{\theta, c r}=0.92 E t^{2.5} R^{-0.5} H^{-1}$

Critical shear buckling MSR: $N_{x \theta, c r}=t \sigma_{x \theta, c r}=0.75 E t^{2.25} R^{-0.75} H^{-0.5}$

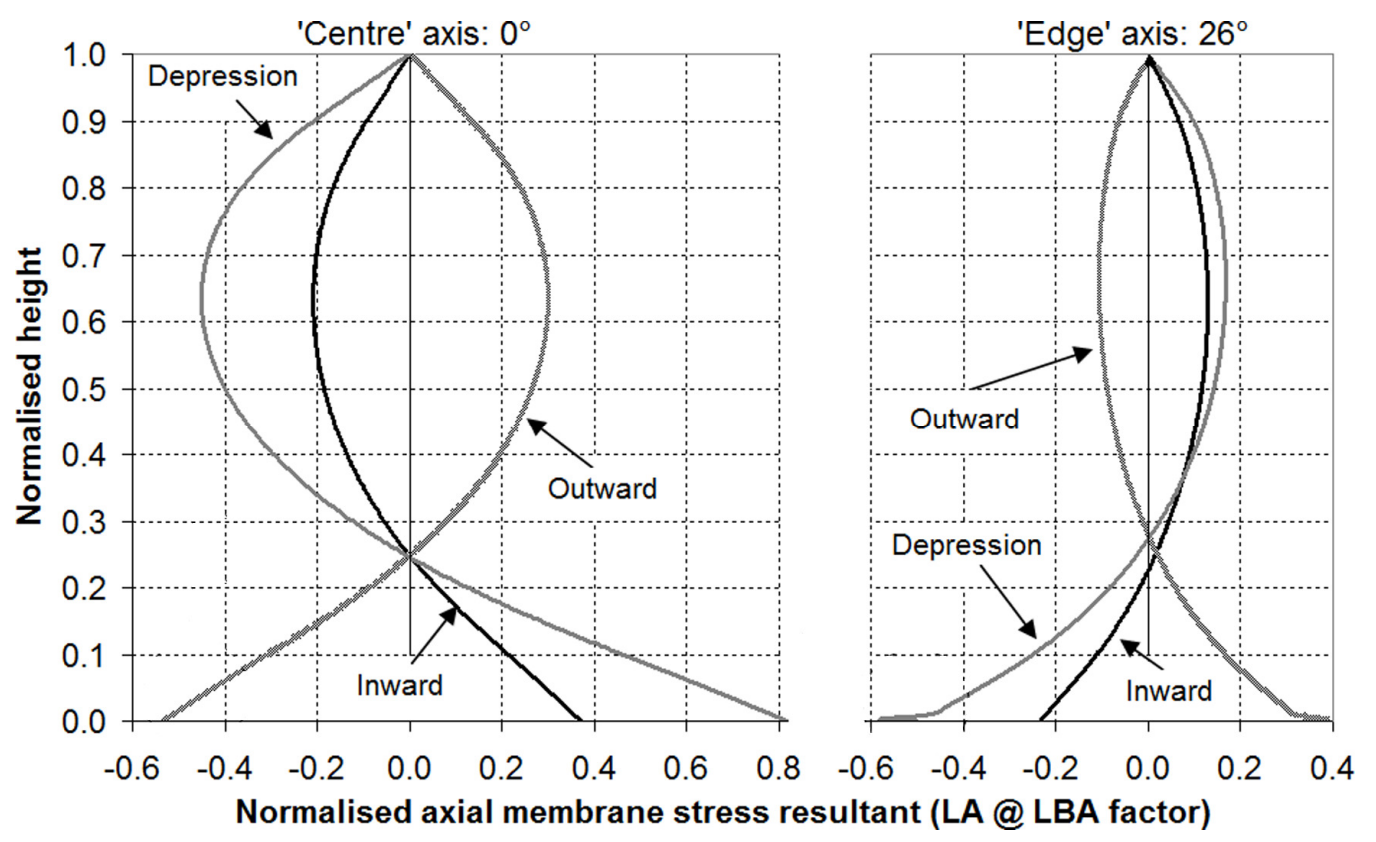

Fig. 5 - Normalised axial membrane stress resultants from LA analyses at LBA buckling at key locations down the meridian 
Published in: Thin-Walled Structures, 61, 169-179.

DOI: http://dx.doi.org/10.1016/j.tws.2012.03.021

For the three different strip loads, the meridional distributions of axial MSRs from LA analyses at LBA buckling are shown in Fig. 5. The distribution through the axis of symmetry at $0^{\circ}$ is shown on the left of the figure and that approximately $26^{\circ}$ on either side of the axis of symmetry is shown on the right. Across the centre of the strip, the inward pressure strip and depression both cause significant axial compression around mid-height and axial tension at the base of the cylinder. Near the edges of the strip, the mid-height compression changes to tension, while the tension near the base becomes compression. The outward pressure strip produces a similar but distinctly reversed effect. The stress distributions at these locations in the cylinder are closely analogous to the extreme fibre stresses in a propped cantilever under a distributed transverse load, suggesting that the loaded strip alone behaves like propped cantilever beam (Gould, 1988).

The axial MSR distributions in Fig. 5 suggest two potentially critical locations for buckling for the inward pressure strip and depression: around mid-height across the centre of the strip (a 'mid-height' buckle) and near the cylinder base across the edge of the strip (a 'base edge' buckle). These correspond closely to those identified for silos under eccentric discharge by Sadowski \& Rotter (2010; 2011a), though the critical location depends on both the wall thickness variation and aspect ratio (Sadowski \& Rotter, 2011b). The highest axial compression for the inward pressure strip and depression occurs near the cylinder base near the strip edge, accompanied by high local shear stresses (not shown). The LBA and GNA analyses identified the 'base edge' and 'mid-height' locations respectively as critical for buckling for the depression, but neither was found to be critical for the inward pressure strip. The critical buckling location for the outward pressure strip was found to be at the cylinder base. 
Published in: Thin-Walled Structures, 61, 169-179.

DOI: http://dx.doi.org/10.1016/j.tws.2012.03.021

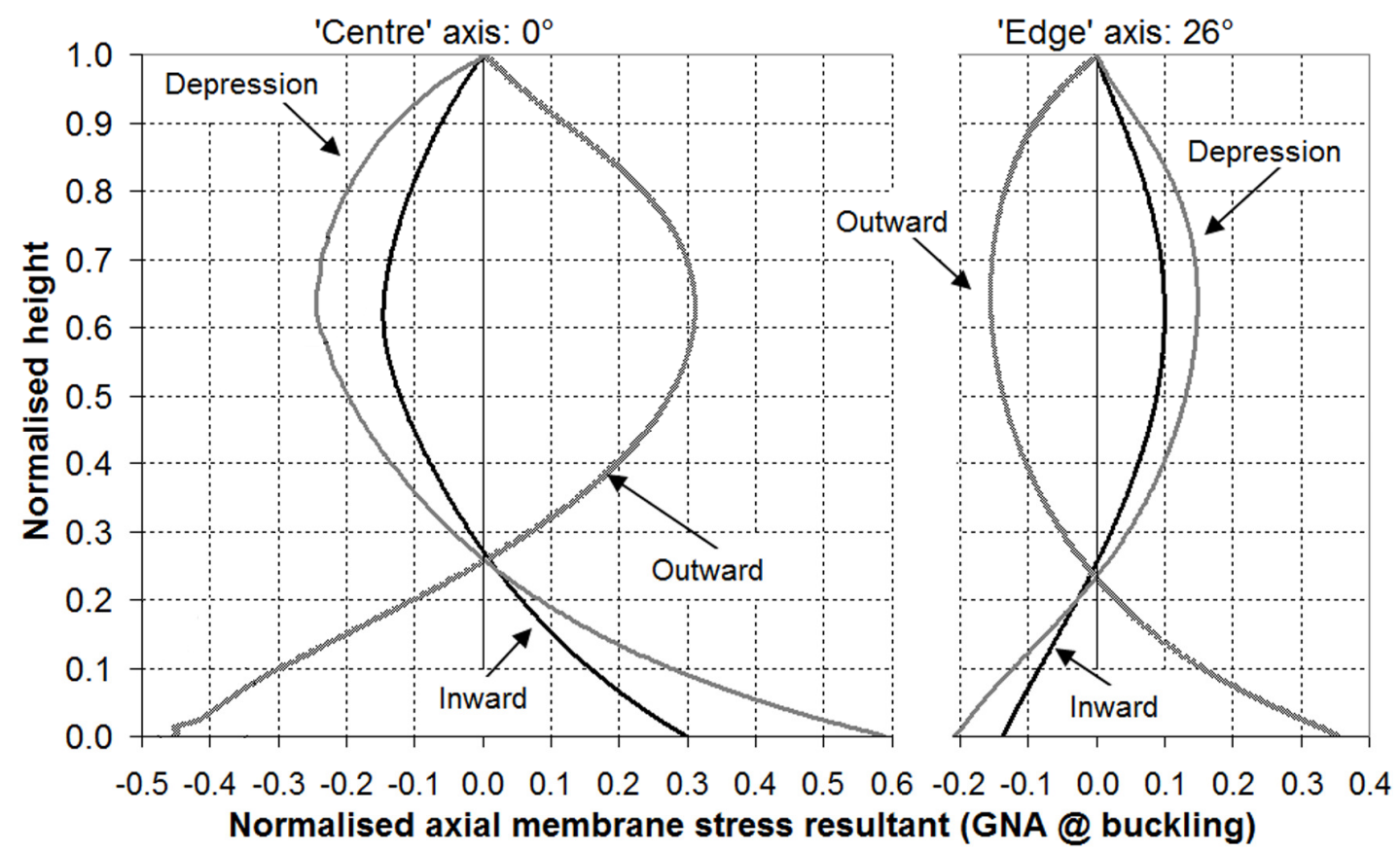

Fig. 6 - Normalised axial membrane stress resultants from GNA analyses at the instant before buckling at key locations down the meridian

The corresponding meridional distribution of axial MSRs from GNA analyses at the instant before bifurcation buckling are shown in Fig. 6. Qualitatively, these show the same features as the LA analyses (Fig. 5), but the critical stress resultant magnitudes are smaller due to local flattening of the cylinder wall, which leads to a larger local radius of curvature. With one exception (shown in the next section), the critical buckling location for each strip load type remains the same. 
Published in: Thin-Walled Structures, 61, 169-179.

DOI: http://dx.doi.org/10.1016/j.tws.2012.03.021

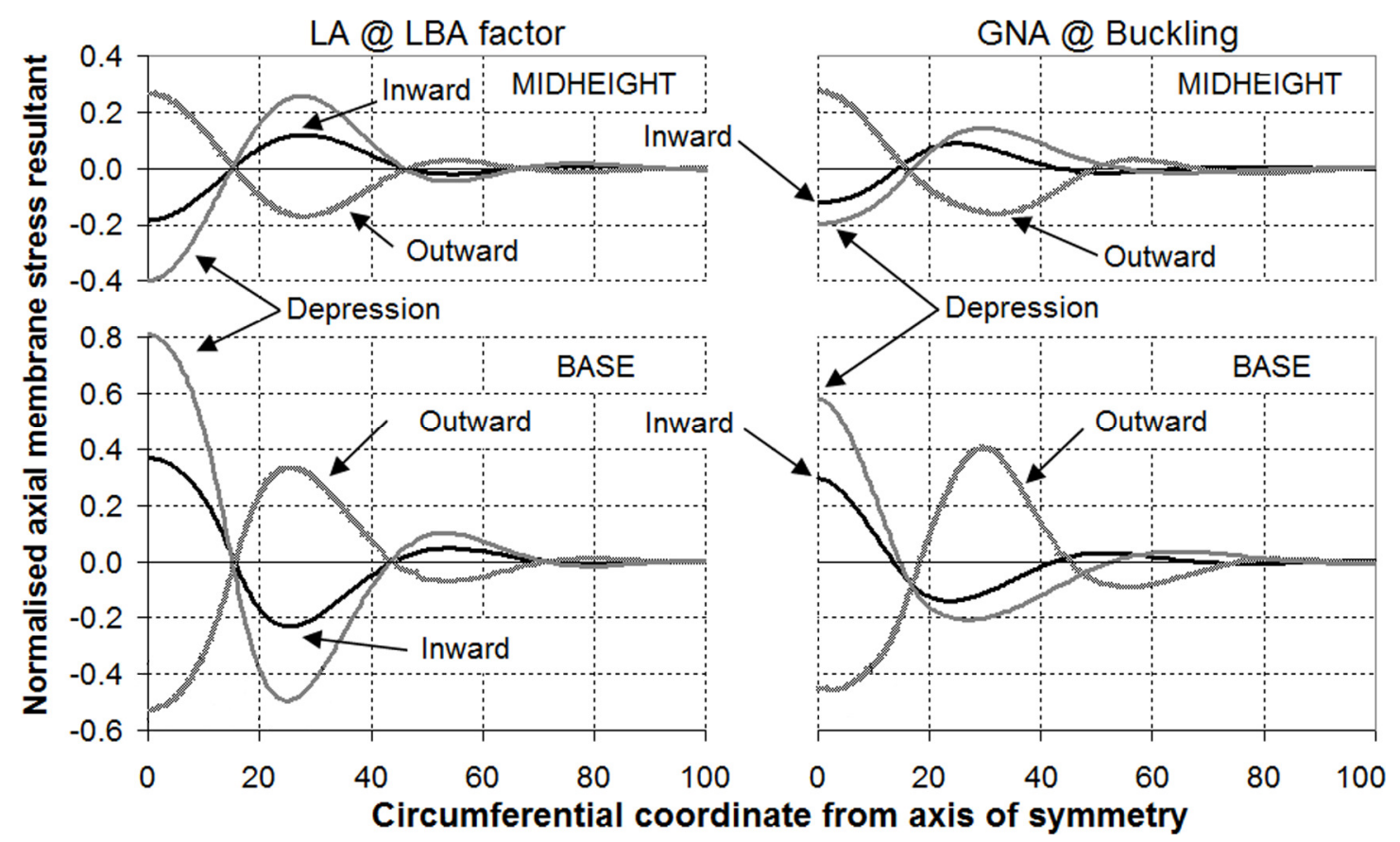

Fig. 7 - Circumferential distribution of normalised axial membrane stress resultants at buckling through the base and mid-height of the cylinder

The circumferential variations of axial MSRs in both LA and GNA analyses at buckling just above the cylinder base and at mid-height (Fig. 7) show that the change from compressive to tensile occurs very rapidly under the action of a strip load. For this strip width, covering $30^{\circ}$ of the full circumference, the stress pattern in the shell extends over no more than about $60^{\circ}$ either side of symmetry axis, beyond which the shell is close to stress free. The most highly-stressed portion is in the immediate vicinity of the strip where the loaded part of the wall acts effectively as a strip beam (Gould, 1988) due to distortion of the complete circular cross-section. 


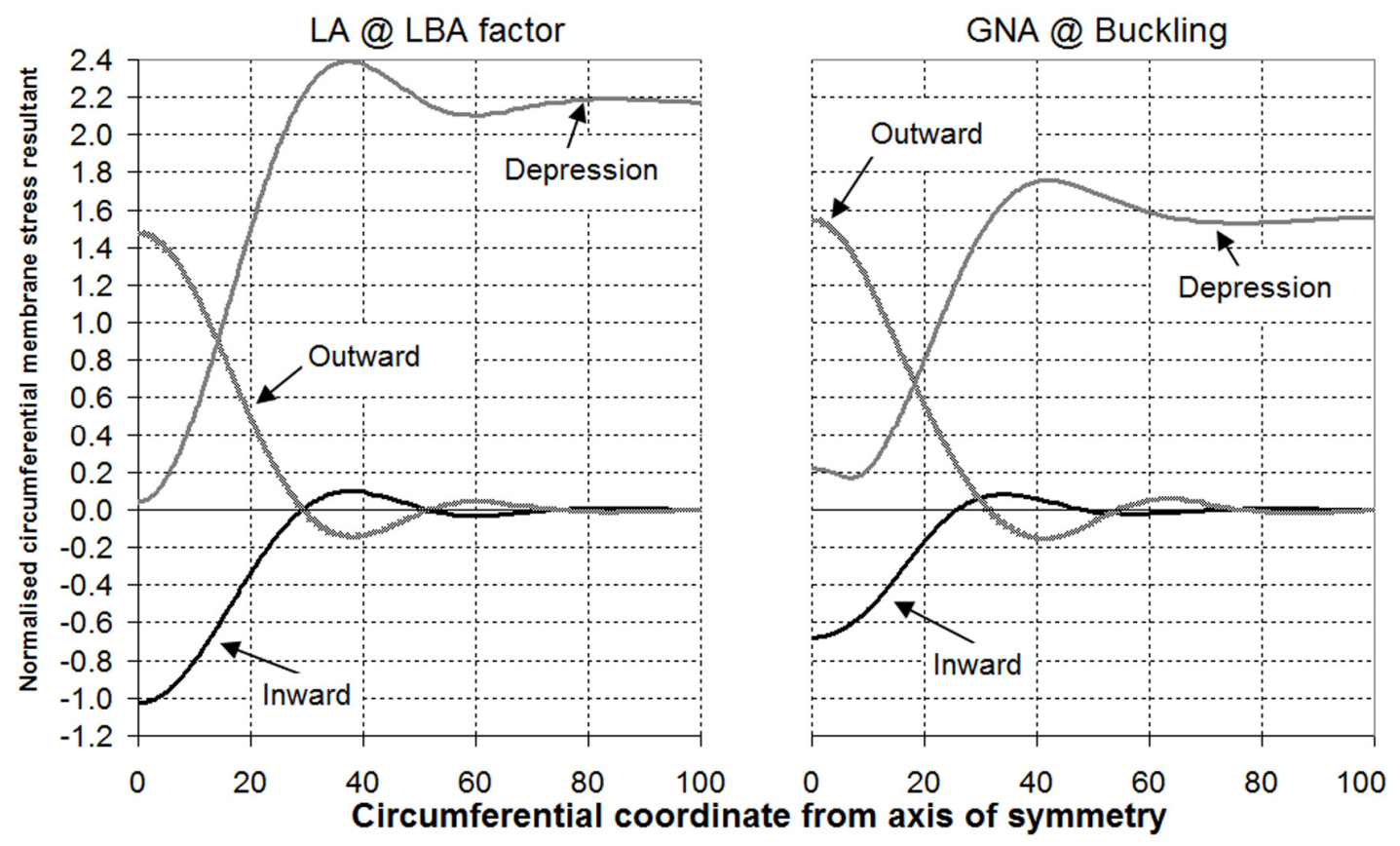

Fig. 8 - Circumferential distribution of normalised circumferential membrane stress resultants at buckling through cylinder mid-height

The circumferential MSRs at mid-height at buckling are shown in Fig. 8. The inward pressure strip causes high circumferential compression that approaches the critical external pressure buckling value (Eq. 2), causing a long-wave global circumferential buckling mode similar to that found in medium-slender silos under wind pressures (Chen \& Rotter, 2012) (Fig. 3). However, the internal pressure throughout most of the circumference in the depression load case causes circumferential tension to develop outside the strip, which effectively cancels the circumferential compression, but not the axial compression, arising from the strip load. Thus the internal pressure outside the strip has a stabilising effect which changes the buckling mode from the external pressure form into a local axial buckling mode at this location (shown in the next section). This mode is similar to that seen in silos under eccentric discharge (Sadowski \& Rotter, 2010; 2011a,b).

Lastly, the outward pressure strip results in extensive circumferential membrane tension across the centre of the strip. Consequently for this load case, the potential failure mode is by material rupture instead of buckling, though this condition lies outside the scope of the present study. Thus a simple reversal in the direction of the 
Published in: Thin-Walled Structures, 61, 169-179.

DOI: http://dx.doi.org/10.1016/j.tws.2012.03.021

pressure on the strip, or the presence or absence of an accompanying uniform internal pressure, causes major changes in the behaviour of the cylinder.

\subsection{Buckling modes and critical load factors}

The predicted linear bifurcation eigenmodes (LBA) and nonlinear incremental buckling modes (GNA) are shown in Figs 9 and 10 respectively. These modes are closely related to the stress patterns described above. Both linear and geometrically nonlinear analyses predict that a local axial compression buckle forms at the foot of the shell under the outward pressure and a global long-wave circumferential buckle under the inward pressure. For the depression, the LBA analysis predict a localised axial/shear compression 'base edge' buckle, while the GNA analysis predicts a localised axial compression 'mid-height' buckle. It is important to recognise that these buckling modes are not caused by applied global axial or shear loading of any kind, but arise solely from unsymmetrical normal pressures.

Table 1 - Summary of predicted load factors for strip half-width $\theta_{\mathrm{s}}=15^{\circ}$

\begin{tabular}{|c|c|c|c|}
\hline Load factor $\left(\times 10^{-4}\right)$ & Outward pressure & Inward pressure & Depression \\
\hline LBA & 5.96 & 4.25 & 8.93 \\
\hline GNA & 8.09 & 1.99 & 7.52 \\
\hline GNA/LBA ratio & 1.36 & 0.47 & 0.84 \\
\hline
\end{tabular}

The cylinder was predicted to buckle at a significantly lower critical pressure under the inward pressure strip than the outward pressure strip (Table 1), which suggests that a local decrease in internal pressure is possibly of greater concern for the stability of thin-walled cylindrical shells than a local increase. A similar conclusion was previously reached for silos under varying pressures during concentric discharge (Rotter, 2008) as well as eccentric discharge and wind load conditions. Oddly, for the outward pressure strip the GNA buckling load is significantly higher than the LBA buckling load. The beneficial effect of pre-buckling deformations on the nonlinear buckling strength of a cylinder under various types of unsymmetrical loads has been reported before (e.g. Song \& Teng, 2003; Sadowski \& Rotter, 2010; 2011a). This effect can be understood when the location of the buckle at the base (Figs 9 and 10) is 
Published in: Thin-Walled Structures, 61, 169-179.

DOI: http://dx.doi.org/10.1016/j.tws.2012.03.021

considered, and it is seen that the magnitude of the compressive membrane stresses at this point are very similar at LBA buckling and at the higher load level of the GNA bifurcation point (Fig. 7).

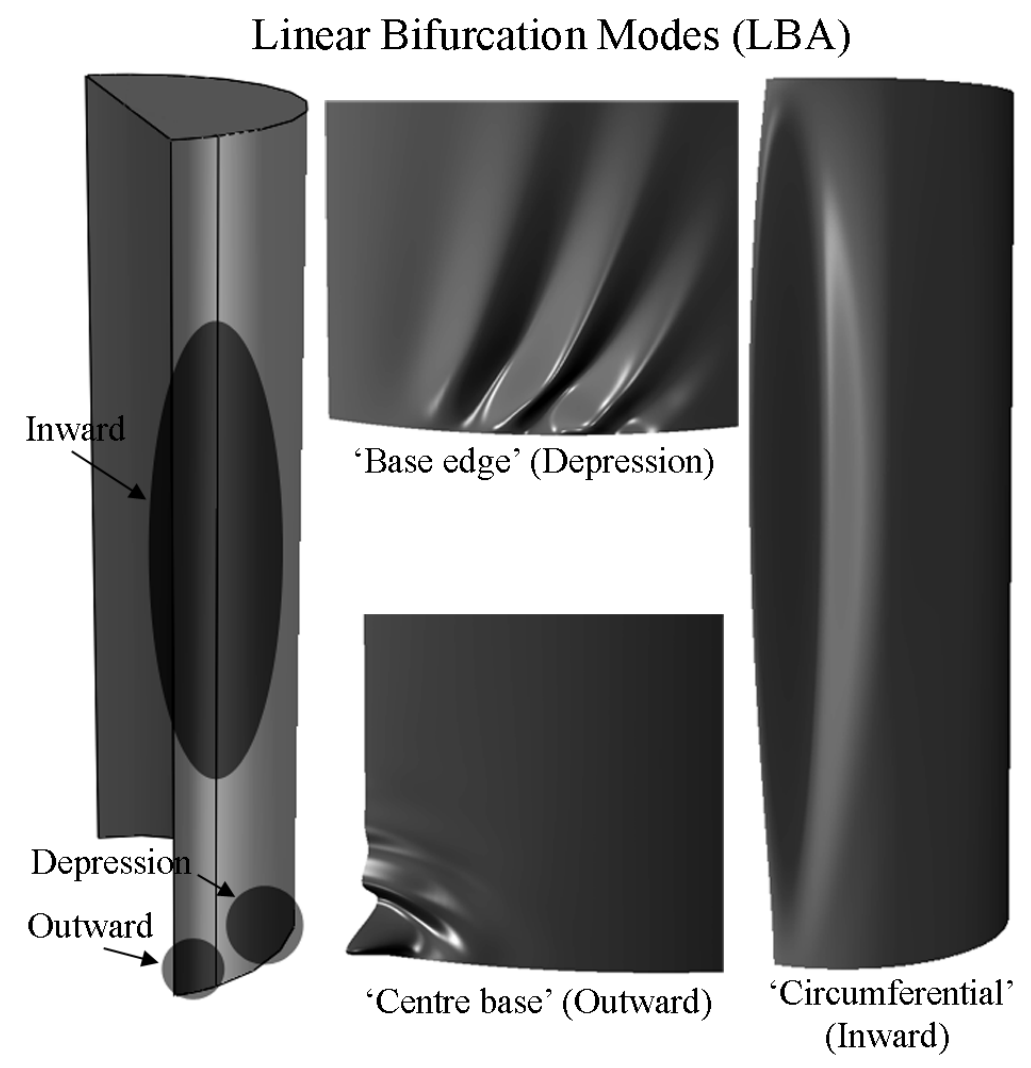

Fig. 9 - Predicted linear bifurcation (LBA) modes 
Published in: Thin-Walled Structures, 61, 169-179.

DOI: http://dx.doi.org/10.1016/j.tws.2012.03.021

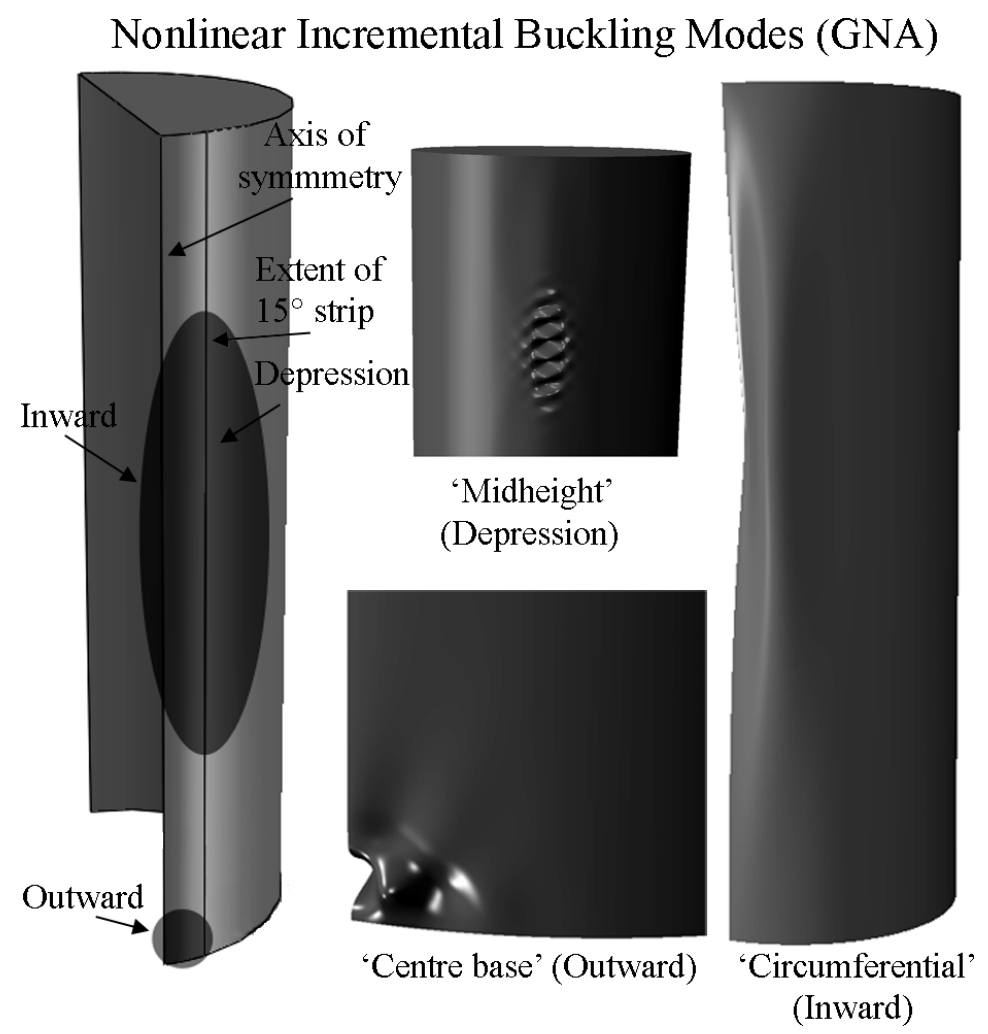

Fig. 10 - Predicted nonlinear incremental buckling (GNA) modes

\subsection{An example of imperfection sensitivity}

A set of calculations was performed using a geometrically nonlinear analysis on an imperfect shell with different imperfection amplitudes (GNIA). For these illustrative analyses, the Type A axisymmetric weld depression of Rotter \& Teng (1989) was placed at mid-height with amplitudes in the range $0.0 \leq \delta / t \leq 1.5$. This imperfection form is generally thought to be one of the most damaging for uniform axial compression and closely represents the common axisymmetric imperfections found in civil engineering shells (Ding et al., 1996; Song et al., 2004, Rotter, 2004; Teng et al., 2005). Since each of the strip loads studied here induces substantial axial compression in the cylinder, it was expected that this imperfection might be quite deleterious. 
Published in: Thin-Walled Structures, 61, 169-179.

DOI: http://dx.doi.org/10.1016/j.tws.2012.03.021

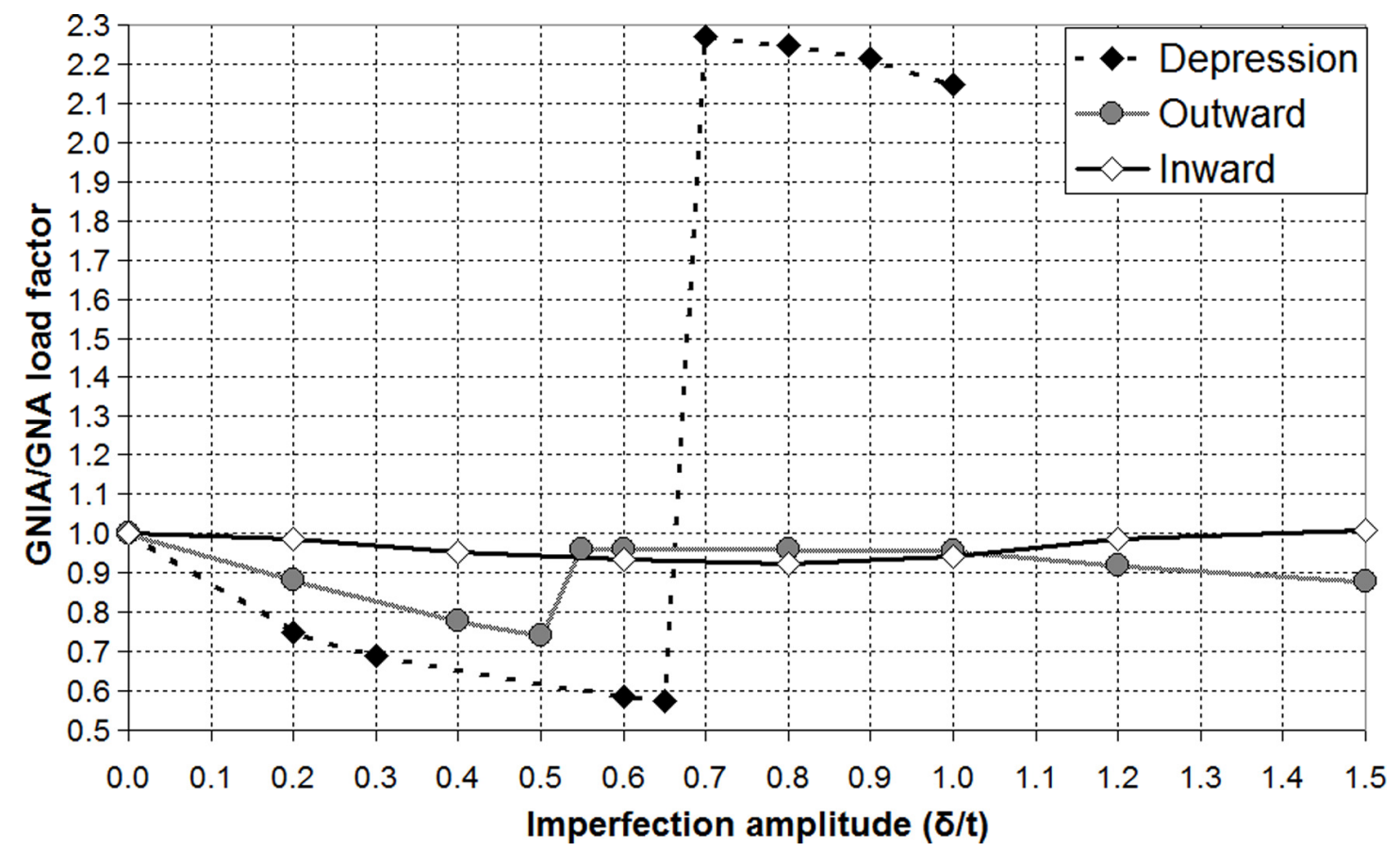

Fig. 11 - Ratio of imperfect to perfect buckling pressure with different imperfection amplitudes (strip width $\theta_{\mathrm{S}}=15^{\circ}$ )

The ratio of the imperfect (GNIA) to perfect (GNA) buckling pressures for different amplitude imperfections is shown in Fig. 11. For the inward pressure strip, the axisymmetric weld depression is seen to have almost no effect on the cylinder buckling strength, and even becomes beneficial at amplitudes greater than $\delta / t \approx 0.8$. For the outward pressure strip, the imperfection is moderately deleterious, reducing the strength to $74 \%$ of the perfect value for amplitudes up to $\delta / t \approx 0.5$, but thereafter a buckling mode change to a different location occurs and this value jumps to $96 \%$. The depression exhibits the same behaviour more dramatically with the drop to $58 \%$ at $\delta / t$ $\approx 0.65$ being followed by a jump to a value $115 \%$ above the perfect strength. In this last case, deeper imperfections are clearly very beneficial to the buckling strength.

Whilst the complete mechanics of the behaviour still hold some secrets, a high imperfection amplitude can be seen to produce a local increase in circumferential bending stiffness (comparable to a corrugation), which restrains the circumferential bending of the cylinder under a strip load. The same behaviour was found in the analysis of slender silos under eccentric discharge (Sadowski, 2010; Sadowski \& Rotter, 2011b). Unfortunately, most design standards that include either tolerances or different strength assessments for different imperfection amplitudes are founded on the 
Published in: Thin-Walled Structures, 61, 169-179.

DOI: http://dx.doi.org/10.1016/j.tws.2012.03.021

general notion that a deeper imperfection will always cause a further reduction in buckling strength. This brief study powerfully demonstrates that an increase in imperfection amplitude does not always lead to a decrease in the buckling strength, and that increases beyond a minimum may not be smooth. The assumption of reducing strength with increasing imperfection amplitude is clearly dependent on both the type of loading and the geometric form of the imperfection.

\section{Strip loads with different circumferential spread}

\subsection{Introduction}

A parametric study was carried out to illustrate the effect of varying the circumferential width of the strip on the resulting patterns of stresses and the elastic buckling modes in the cylinder. Sets of LA, LBA and GNA analyses were performed on each of the three defined strip loads, with strip half-width angles $\theta_{\mathrm{s}}$ of $7.5^{\circ}, 15^{\circ}, 22.5^{\circ}, 30^{\circ}$ and $45^{\circ}$. The $45^{\circ}$ half angle represents a very wide strip load, acting on a quarter of the circumference. Due to space constraints, the chief focus here is on the linear elastic response.

\subsection{The inward pressure strip}

A narrow inward pressure strip was previously shown (Fig. 7) to cause significant axial and circumferential compression across the centre of the strip at about midheight. In linear analyses, the compressive peak in both the axial and circumferential MSRs (Figs 12 and 13) occurs only for strip widths up to a half angle of about $\theta_{\mathrm{s}}=25^{\circ}$. Thereafter, the pattern becomes significantly more complex as these stresses oscillate. The stress patterns for wide strips are more closely related to the pressure discontinuity at the strip edge (causing local bending there) than to the effect of a line load (illustrated by the narrowest strip with $\theta_{\mathrm{s}}=15^{\circ}$ ). As the strip becomes wider, the global LBA buckling mode remains similar to that in Fig. 9 and grows in circumferential extent as the central region of compressive circumferential MSRs enlarges (Fig. 13). 
Published in: Thin-Walled Structures, 61, 169-179.

DOI: http://dx.doi.org/10.1016/j.tws.2012.03.021

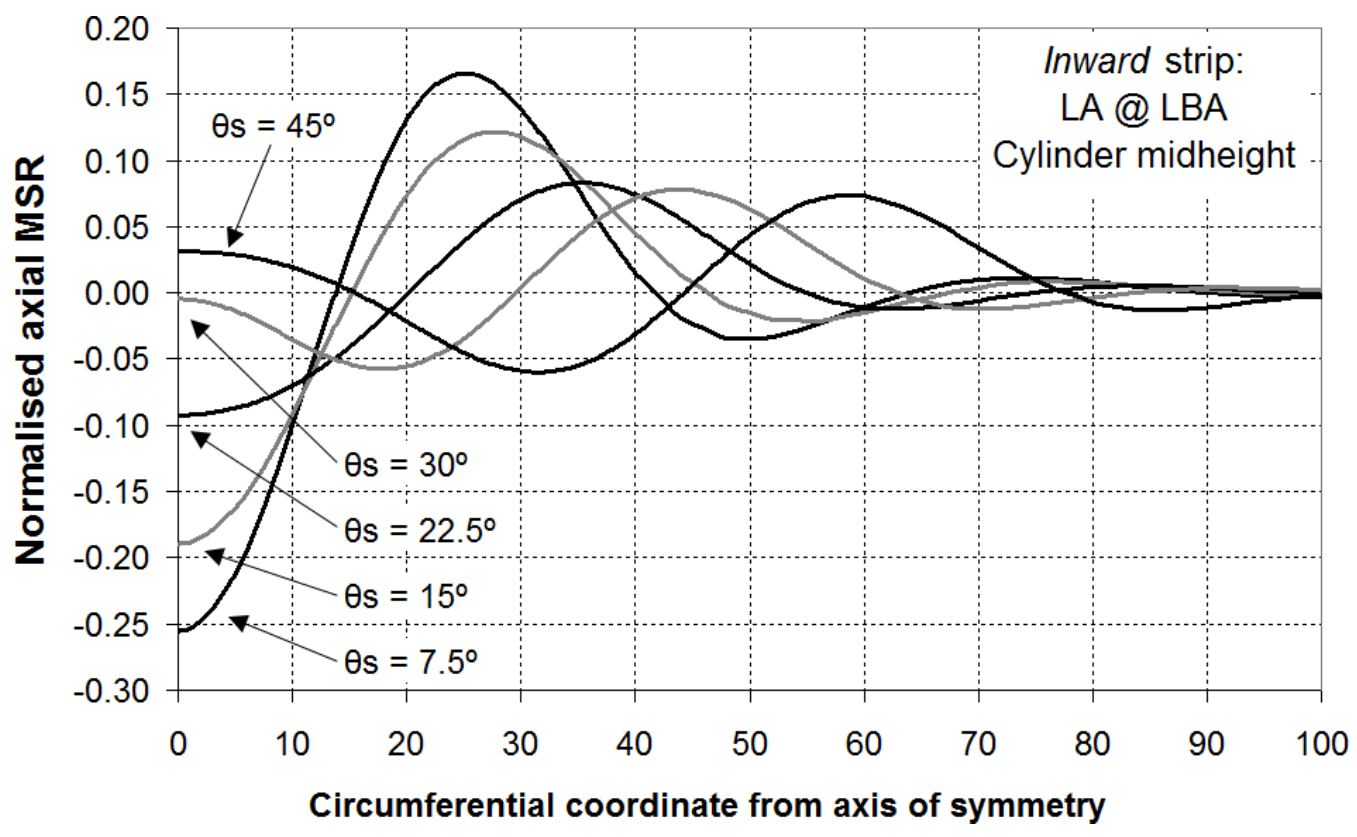

Fig. 12 - Circumferential patterns of normalised axial MSR at mid-height, with changing with strip half-angle $\theta_{\mathrm{S}}$

(LA analyses at LBA buckling for the inward pressure strip)

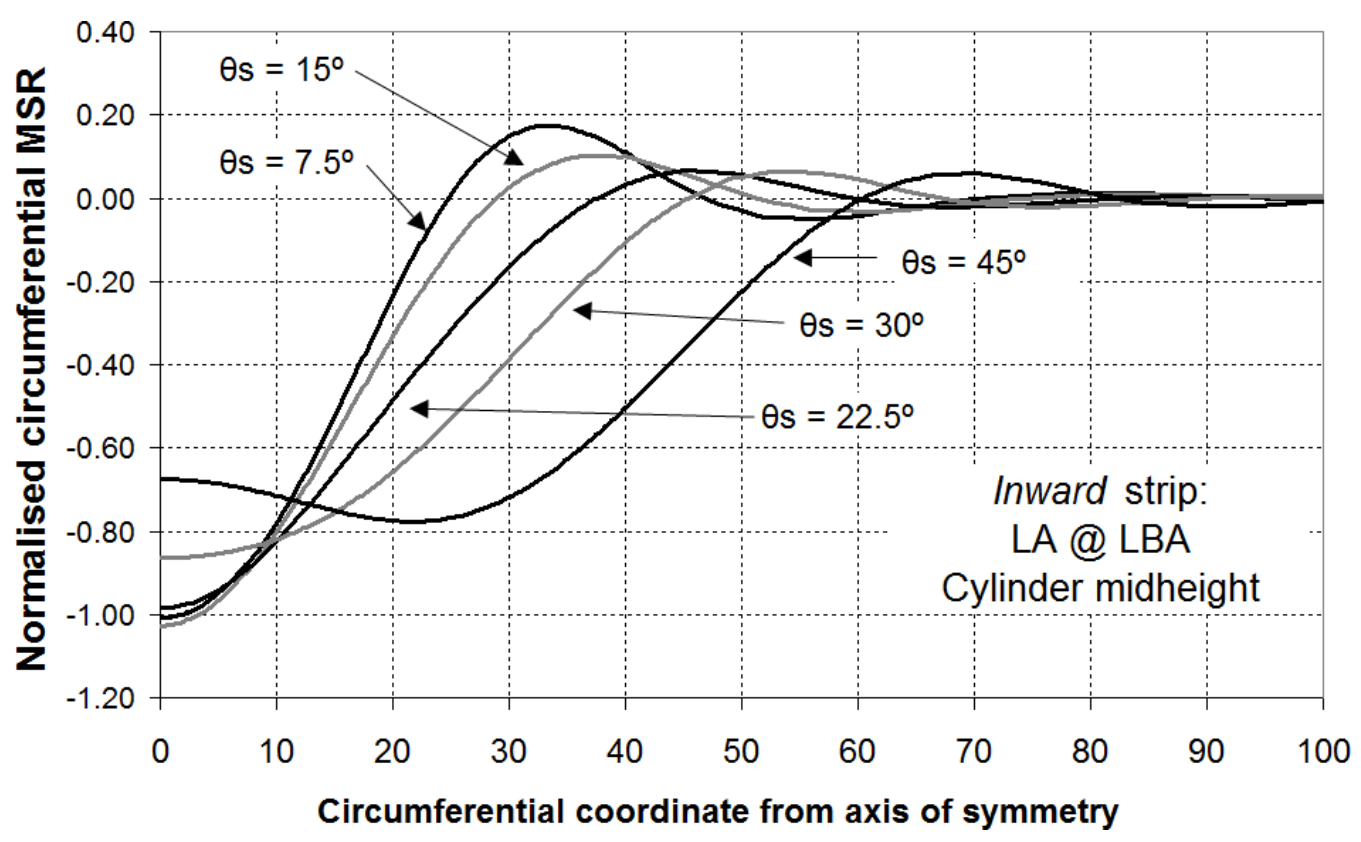

Fig. 13 - Circumferential patterns of normalised circumferential MSR at mid-height, with changing with strip half-angle $\theta_{\mathrm{S}}$ (LA analyses at LBA buckling for the inward pressure strip)

Geometric nonlinearity significantly modifies these stress patterns (compare Figs 12 and 14, Figs 13 and 15). Once the strip begins to widen, geometric nonlinearity causes 
Published in: Thin-Walled Structures, 61, 169-179.

DOI: http://dx.doi.org/10.1016/j.tws.2012.03.021

the oscillation in axial stresses to be exaggerated, and for $\theta_{\mathrm{s}}=30^{\circ}$, for example, a zero axial MSR (LA) on the central meridian becomes very tensile (GNA). By contrast, the circumferential MSRs simply spread over wider zones. The GNA incremental buckling modes (Fig. 16) are quite sensitive to the precise shape of the stresses, changing between the circumferential compression global long-wave buckle (Fig. 15), the local short-wave axial compression 'mid-height' buckle (Fig. 13) and interactions of the two. The load factors for both the LBA and GNA analyses are shown in Fig. 17, where the LBA load factor decreases but the GNA value is stable as the strip width increases. For this inward pressure strip, these changes indicate a diminishing sensitivity to geometric nonlinearity as the loaded zone increases in size.

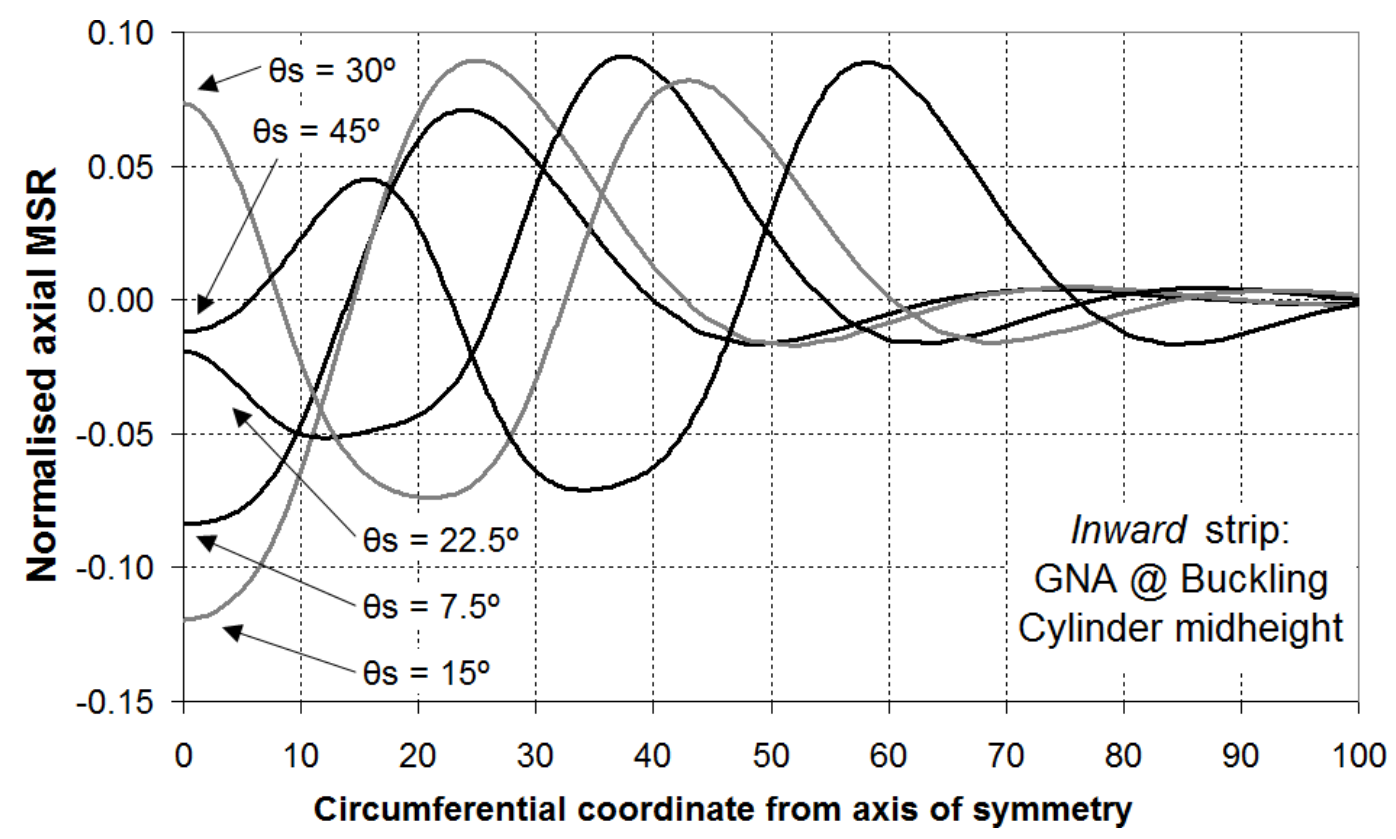

Fig. 14 - Circumferential patterns of normalised axial MSR at mid-height, with changing with strip half-angle $\theta_{\mathrm{S}}$

(GNA analyses at the instant before buckling for the inward pressure strip) 
Published in: Thin-Walled Structures, 61, 169-179.

DOI: http://dx.doi.org/10.1016/j.tws.2012.03.021

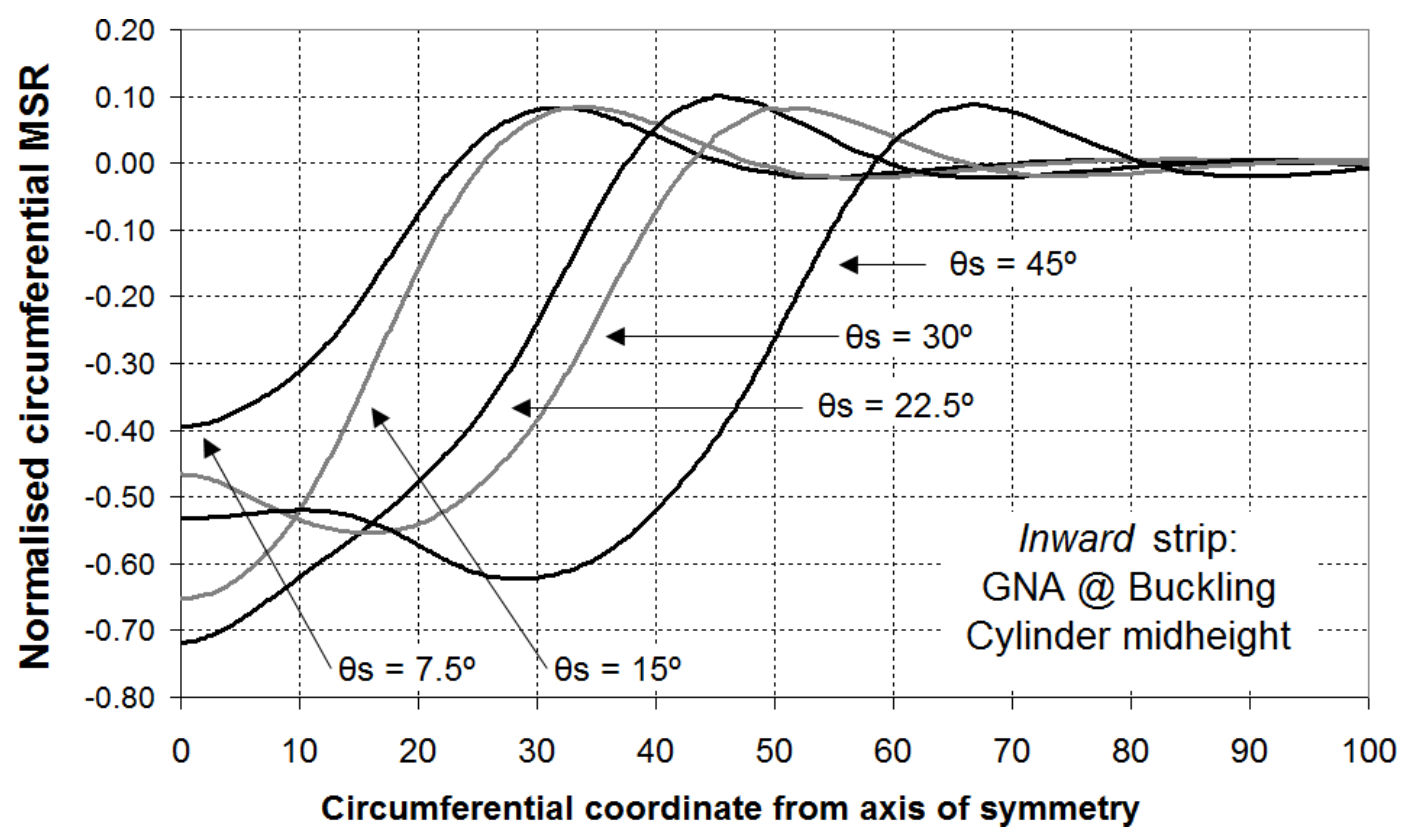

Fig. 15 - Circumferential patterns of normalised circumferential MSR at mid-height, with changing with strip half-angle $\theta_{\mathrm{S}}$

(GNA analyses at the instant before buckling for the inward pressure strip)

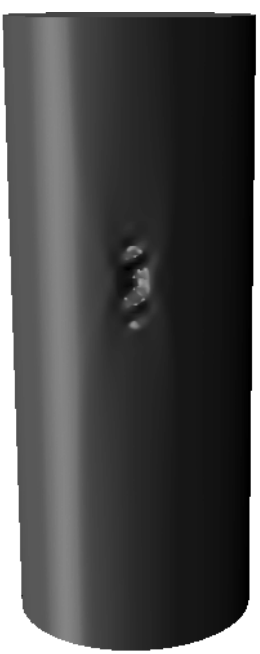

$\theta \mathrm{s}=7.5^{\circ}$

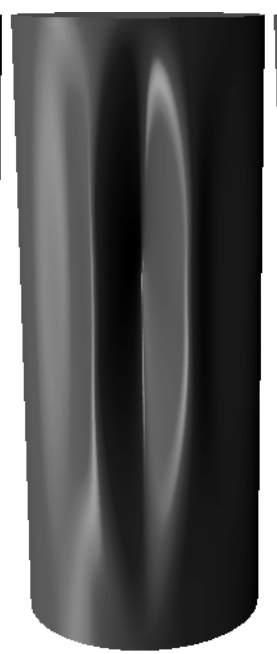

$\theta \mathrm{s}=15^{\circ}$

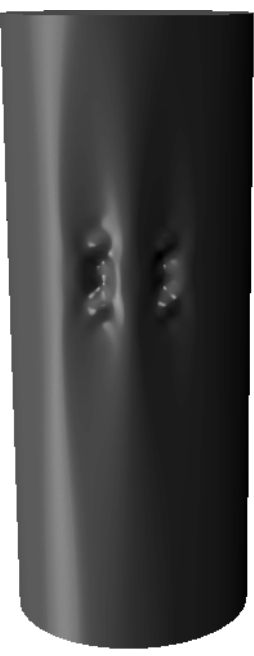

$\theta \mathrm{s}=22.5^{\circ}$

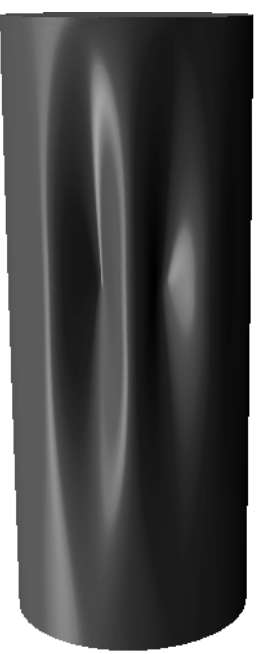

$\theta \mathrm{s}=30^{\circ}$

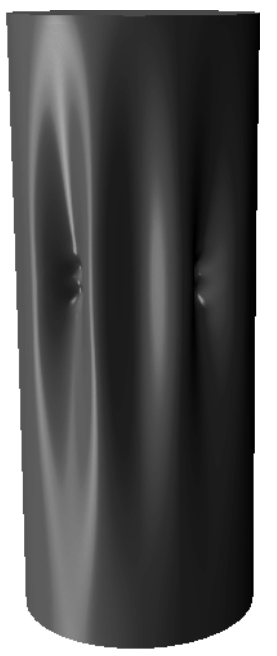

$\theta \mathrm{s}=45^{\circ}$

Fig. 16 - Variation of GNA nonlinear incremental buckling modes with strip halfangle $\theta_{\mathrm{s}}$ for the inward pressure strip 
Published in: Thin-Walled Structures, 61, 169-179.

DOI: http://dx.doi.org/10.1016/j.tws.2012.03.021

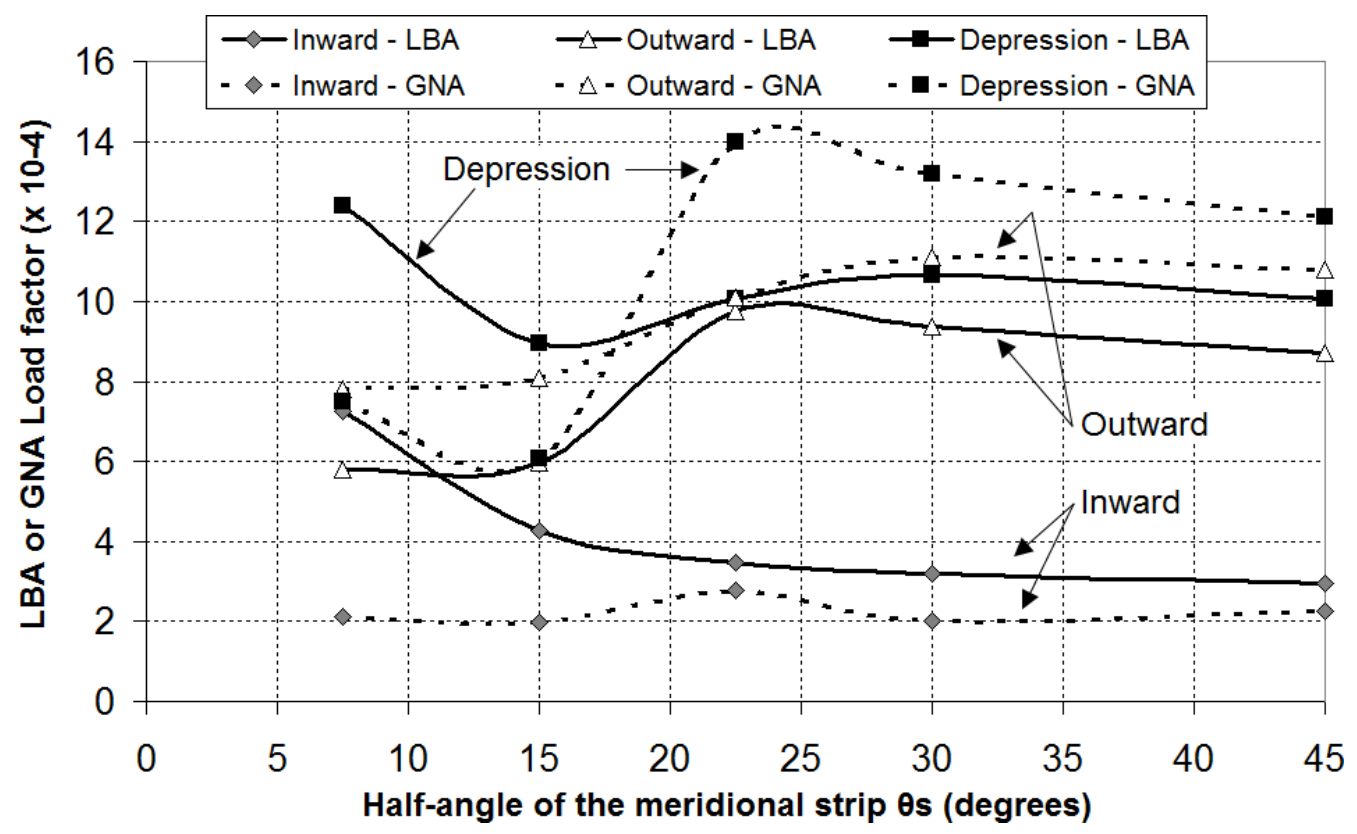

Fig. 17 - Variation of LBA and GNA buckling load factors with strip half-angle $\theta_{\mathrm{s}}$ for the three strip loads

\subsection{The outward pressure strip}

A narrow outward pressure strip was previously shown (Figs 5 to 7) to lead to a midheight peak in axial and circumferential tension across the centre of the strip, together with greatly increased axial compression at the foot of the strip causing a local buckle at this location (Figs $9 \& 10$ ). Increasing the circumferential spread of the strip increases the central region of axial compression at the cylinder base and causes its peak to displace away from the central axis (Fig. 18). A much more important peak in the shear MSR develops at the strip edge (Fig. 19), due to the incompatibility of membrane displacements, as noted by Song et al. (2004). It may also be noted that this peak shear greatly exceeds the value for uniform torsion, but it acts on a very small zone. This clearly illustrates the increased buckling resistance that develops when the peak stresses act on a much smaller region than the size of the zone required for a classical uniform stress buckle. For $\theta_{\mathrm{s}} \geq 22.5^{\circ}$, the increasing shear peak begins to overlap somewhat with the axial compression peak, causing a significant change in the LBA buckling mode from a local axial compression buckle to a large shear buckle (Fig. 20) and a corresponding sudden jump in the buckling pressure (Fig. 17). The shear buckling mode is similar to that found in slender silos under wind pressures (Chen \& Rotter, 2012). 
Published in: Thin-Walled Structures, 61, 169-179.

DOI: http://dx.doi.org/10.1016/j.tws.2012.03.021

The stress distributions from GNA analyses (not shown) exhibit similar features though the magnitudes change, but they indicate that geometric nonlinearity is beneficial to the buckling pressure for a wide range of strip widths. Previous studies of silos under eccentric discharge which assumed a local increase in normal pressure (i.e. outward) (Song \& Teng, 2003) also found this effect. As shown in Fig. 17, the beneficial effect is relatively invariant with strip width, but is not reliable at all widths.

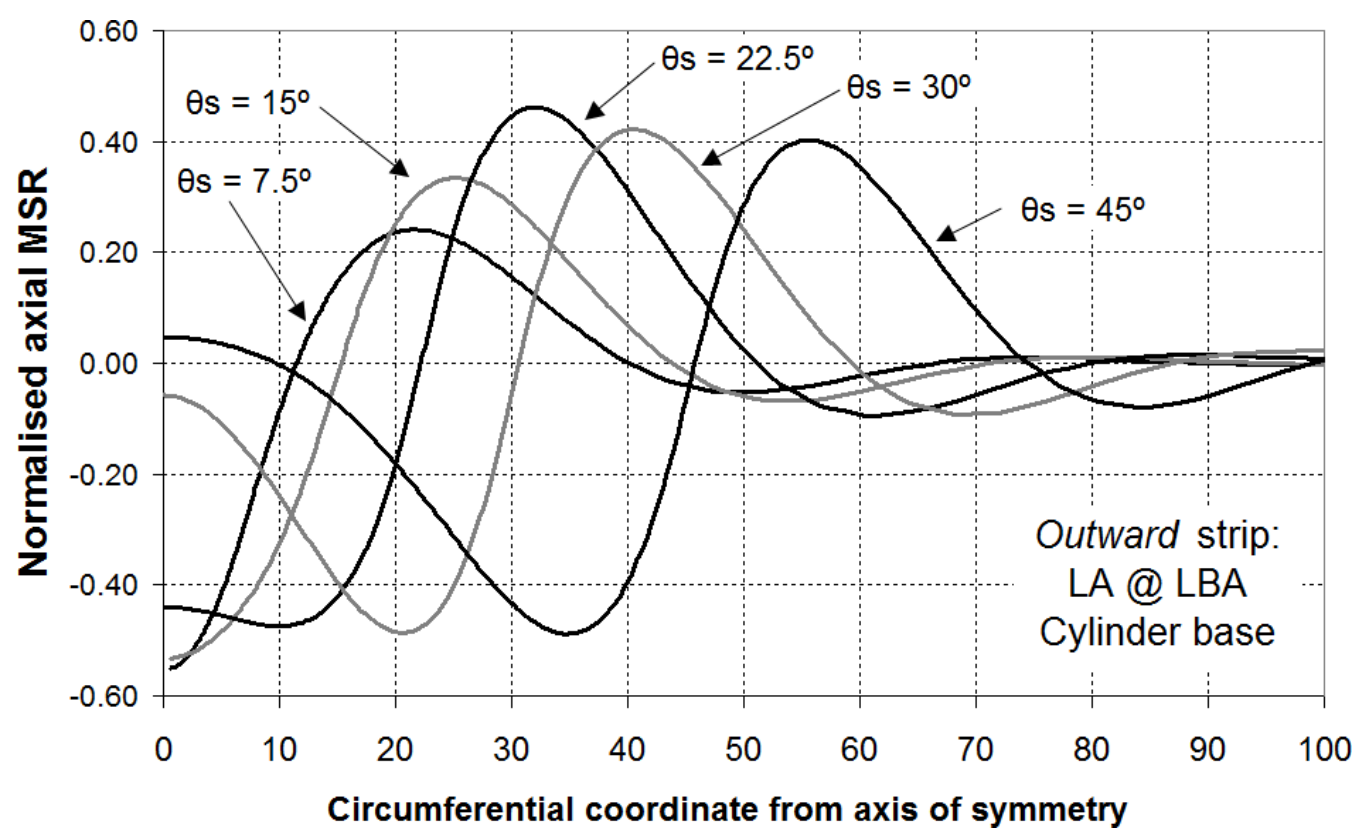

Fig. 18 - Circumferential patterns of normalised axial MSR at base, with changing with strip half-angle $\theta_{\mathrm{S}}$

(LA analyses at LBA buckling for the outward pressure strip) 
Published in: Thin-Walled Structures, 61, 169-179.

DOI: http://dx.doi.org/10.1016/j.tws.2012.03.021

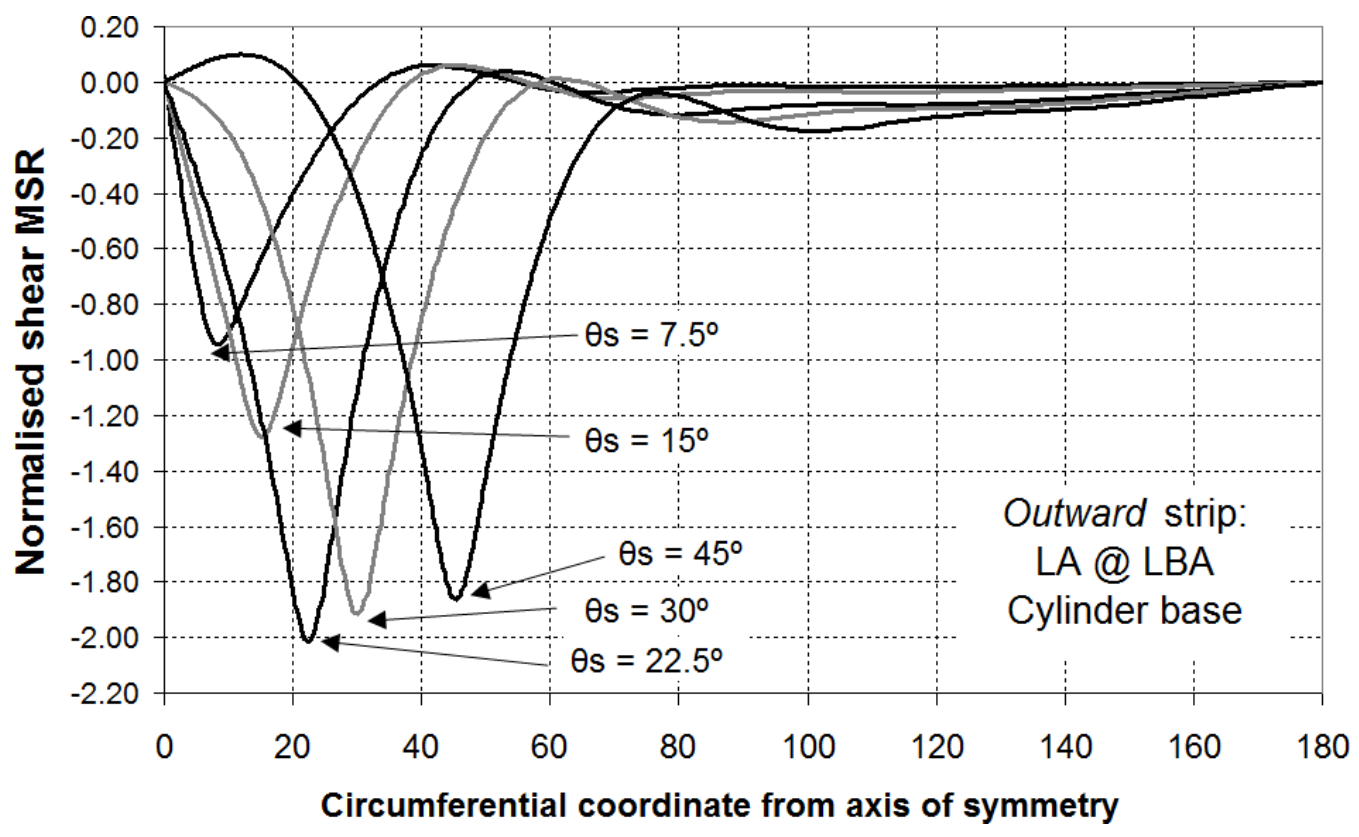

Fig. 19 - Circumferential patterns of normalised shear MSR at base, with changing with strip half-angle $\theta_{\mathrm{S}}$

(LA analyses at LBA buckling for the outward pressure strip)
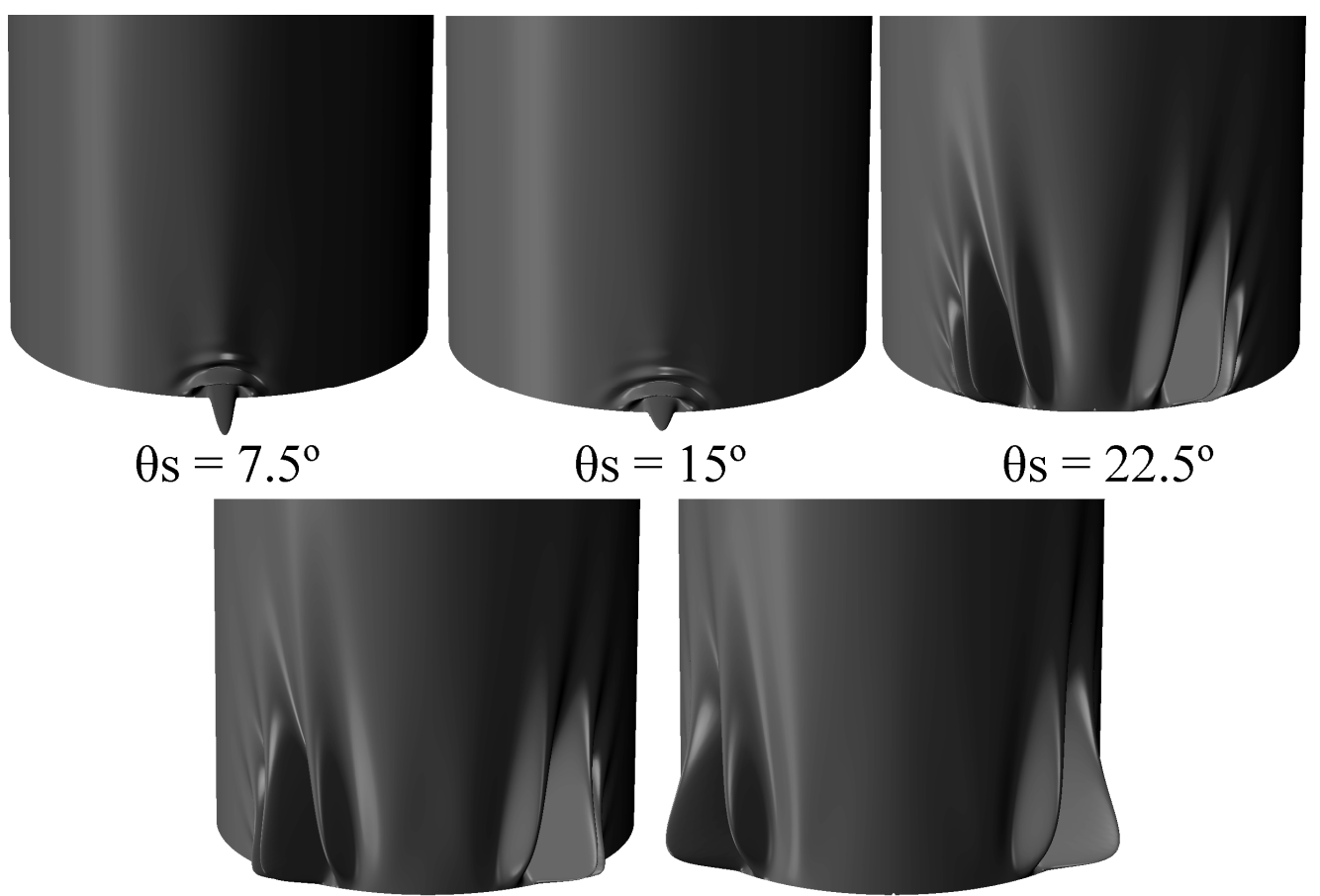

$\theta \mathrm{s}=15^{\circ}$

$\theta \mathrm{s}=22.5^{\circ}$

$$
\theta \mathrm{s}=30^{\circ}
$$

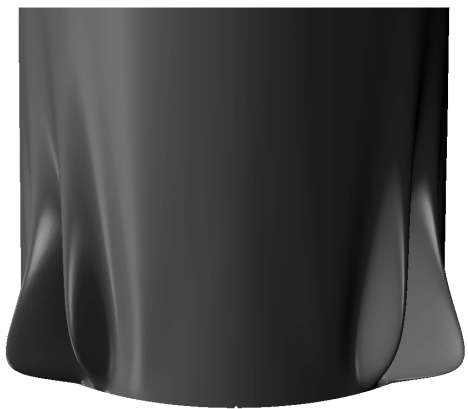

$$
\theta \mathrm{s}=45^{\circ}
$$

Fig. 20 - Variation of LBA linear bifurcation eigenmodes with strip half-angle $\theta_{\mathrm{s}}$ for the outward pressure strip 
Published in: Thin-Walled Structures, 61, 169-179.

DOI: http://dx.doi.org/10.1016/j.tws.2012.03.021

\subsection{The strip depression}

Under a narrow strip depression (Fig. 4), the stress patterns in the cylinder are characterised by a local peak in axial compression at two potentially critical locations (Figs 5 to 7), similar to that of the inward pressure strip. However, significant stabilisation is provided by the circumferential tension outside the strip (Fig. 8). The LBA and GNA buckling modes (Figs 9 and 10) respectively exhibit a mixed axial compression and shear buckle near the cylinder base at the strip edge (with the centre of the strip being under axial tension there) and an axial compression buckle across the centre of the strip near mid-height. As the strip width increases, the peaks of axial compression (Fig. 21) and shear (Fig. 22) displace further around the circumference away from the axis of symmetry, leading to consequent changes in the position and size of the local LBA buckle, whose general shape is shown in Fig. 23. The peak shear MSR again greatly exceeds the value for uniform torsion even for narrow strips, acting on a very small zone, and demonstrates the importance of the spread of peak stresses on the value at which buckling occurs.

Geometric nonlinearity does not change either of the stress patterns significantly, but it significantly adjusts the relative magnitudes of the stresses. As a result there is a change in the predicted buckling mode from a 'mid-height' axial compression buckle for $\theta_{\mathrm{s}} \leq 15^{\circ}$ (similar to silos under eccentric discharge) to a strip edge shear buckle at the base for $\theta_{\mathrm{s}} \geq 22.5^{\circ}$ (Fig. 23). This leads to a significant jump in the GNA load factor between $\theta_{\mathrm{s}}=15^{\circ}$ and $22.5^{\circ}$ (Fig. 17), and the effects of geometric nonlinearity change from deleterious to beneficial. 
Published in: Thin-Walled Structures, 61, 169-179.

DOI: http://dx.doi.org/10.1016/j.tws.2012.03.021

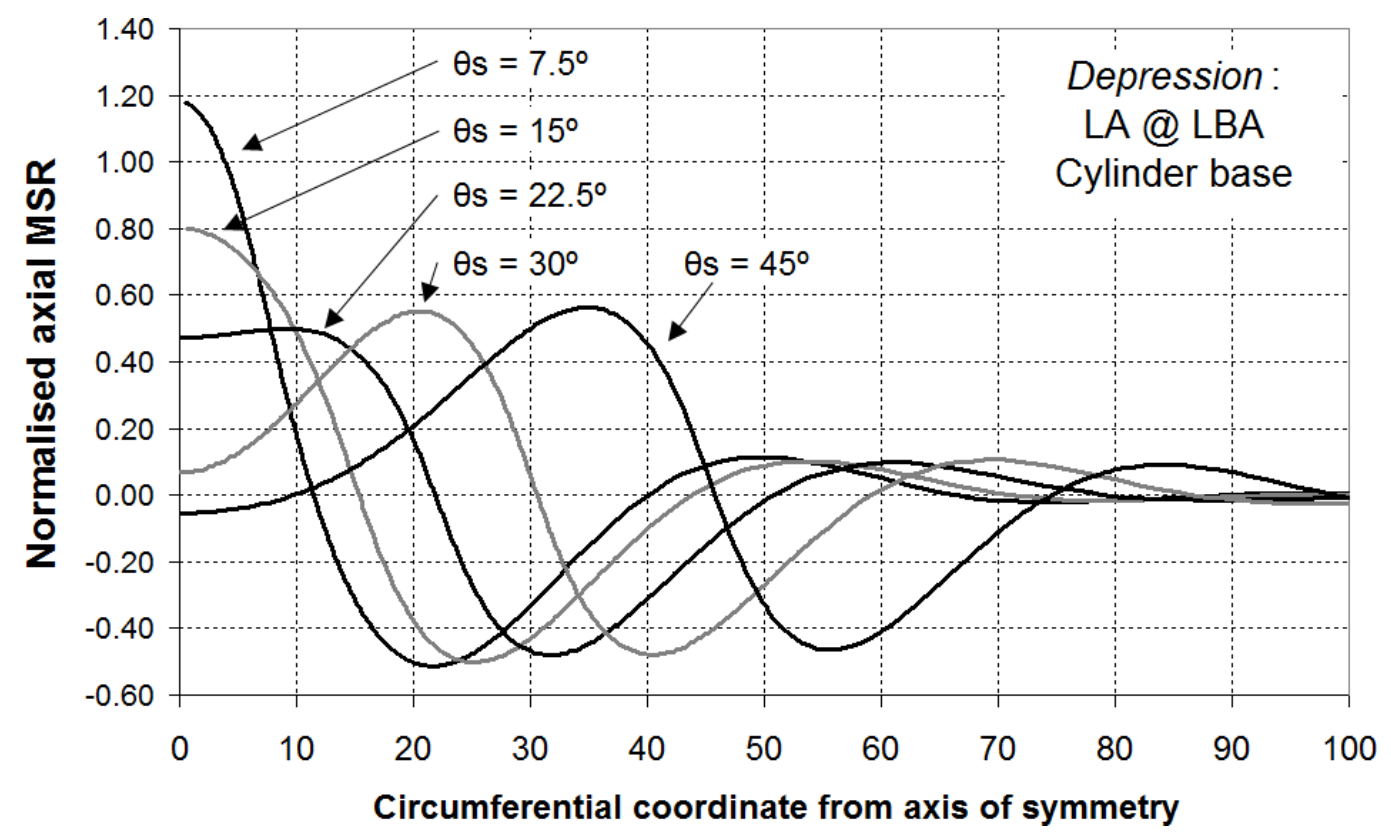

Fig. 21 - Circumferential patterns of normalised axial MSR at base, with changing with strip half-angle $\theta_{\mathrm{S}}$

(LA analyses at LBA buckling for the depression)

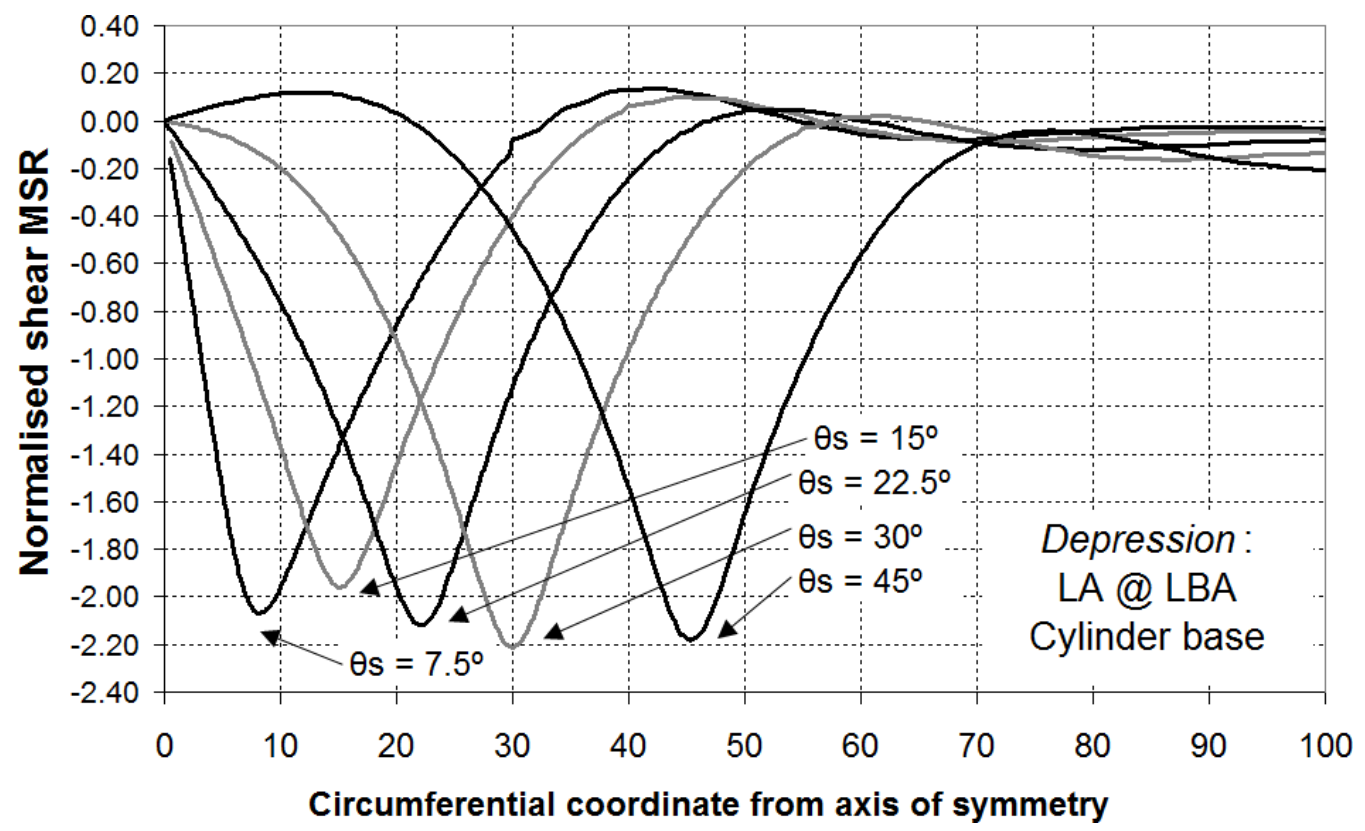

Fig. 22 - Circumferential patterns of normalised shear MSR at base, with changing with strip half-angle $\theta_{\mathrm{S}}$ (LA analyses at LBA buckling for the depression) 
Published in: Thin-Walled Structures, 61, 169-179.

DOI: http://dx.doi.org/10.1016/j.tws.2012.03.021

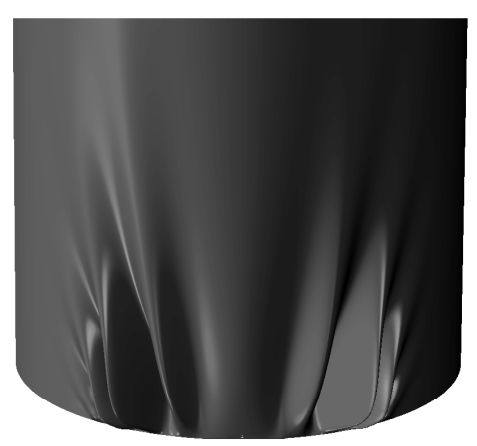

Consistent type of

LBA buckling mode for all values $\theta$ s

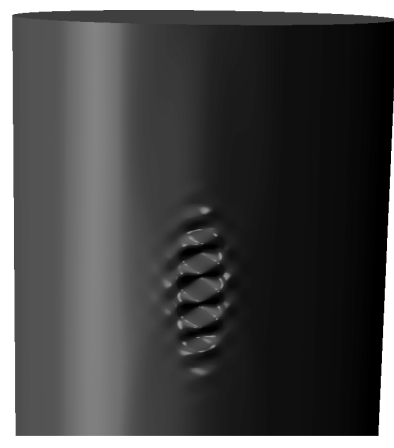

GNA 'midheight' buckling mode type for $\theta \mathrm{s} \leq 15^{\circ}$

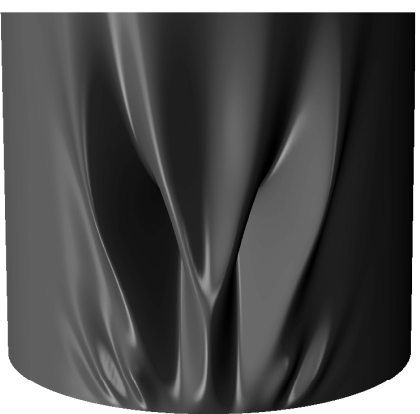

GNA bottom buckling mode type for $\theta \mathrm{s} \geq 22.5^{\circ}$

Fig. 23 - Summary of LBA and GNA buckling mode types as a function of the strip half-angle $\theta_{\mathrm{s}}$ for the depression

\section{Conclusions}

This paper has illustrated some selected aspects of the complex behaviour of a slender thin-walled cylinder under three different patterns of normal pressure on a meridional strip. This pattern of loading was defined to emulate but generalise key features of several forms of unsymmetrical loads on silos and tanks. The linear and nonlinear stress patterns, buckling modes and buckling strengths were explored.

The main conclusions are as follows:

- A meridional strip of normal pressure with no additional axial or circumferential loading was found to have a very significant and deleterious effect on the structural behaviour of a perfect thin-walled cylinder.

- The structural effects of such loads depend very much on the inward or outward direction of the pressures on the strip and on whether this load is superimposed on a uniform internal pressure loading.

- The effect of geometric nonlinearity on the buckling of shells under unsymmetrical load patterns is often much more significant than that under axisymmetric load patterns.

- Under inward local pressures, geometric nonlinearity appears to consistently reduce the buckling pressure. Under outward local pressures, it causes increases in the buckling pressure, but these are not always reliable. Under an axisymmetric outward (i.e. internal) pressure with a local depression imperfection, it is detrimental on narrow strips, but beneficial on wide ones. 
Published in: Thin-Walled Structures, 61, 169-179.

DOI: http://dx.doi.org/10.1016/j.tws.2012.03.021

- Understanding these effects is critical to the improved formulation of buckling strength rules in standards, to permit the LBA-MNA procedure to be used for unusual load cases with confidence.

- Nevertheless, this study has shown that geometrically nonlinear phenomena are complex in cylindrical shells under unsymmetrical loads and more research is needed to understand the mechanics of the behaviour in detail, including the critical effects of aspect ratio, changes in shell wall thickness and material nonlinearity.

\section{Acknowledgements}

Part of this paper was published in the Proceedings of the $6^{\text {th }}$ International Conference on Thin-Walled Structures held in Timisoara, Romania, on September 5-7, 2011. The authors are grateful for the invitation to submit this larger study for publication in a special issue of Thin-Walled Structures.

\section{References}

ABAQUS (2009). “ABAQUS Version 6.9” Dassault Systèmes Simulia Corp., Providence, RI, USA.

Abir, D. and Nardo, S.V. (1958) "Thermal Buckling of Circular Cylindrical Shells under Circumferential Temperature Gradients”, J. Aerospace Sci., 26(12), pp 803-808.

Bushnell, D. and Smith, S. (1971) "Stress and Buckling of Non-Uniformly Heated Cylindrical and Conical Shells", AIAA J. 9, pp. 2314-2321.

Calladine C.R. (1983). "Theory of Shell Structures." Cambridge University Press, Cambridge.

Chen L. (2011). "Buckling of cylindrical shells under different load conditions" PhD Thesis, The University of Edinburgh. 
Published in: Thin-Walled Structures, 61, 169-179.

DOI: http://dx.doi.org/10.1016/j.tws.2012.03.021

Chen L. \& Rotter J.M. (2012). "Buckling of anchored cylindrical shells of uniform thickness under wind load." Under review - Submitted for publication on 22/06/11 to Engineering Structures.

Chen J.F., Rotter J.M. \& Ooi J.Y. (1998). "Statistical inference of unsymmetrical silo pressures from comprehensive wall strain measurements." Thin-Walled Structures, 31, 117-136.

DIN 18800 (1990). Stahlbauten: Stabilitätsfälle, Schalenbeulen, DIN 18800 Part 4, Deutsches Institut für Normung, Berlin, November, 22pp.

Ding X.L., Coleman R.D. \& Rotter J.M. (1996). “Technique for precise measurement of large-scale silos and tanks.” ASCE Jrnl. of Surveying Engineering, 122, 14-25.

ECCS EDR5 (2008) "Stability of Steel Shells: European Design Recommendations: Fifth Edition", Eds J.M. Rotter and H. Schmidt, H., Publication P125, European Convention for Constructional Steelwork, Brussels.

EN 1991-4 (2006). "Eurocode 1 - Actions on structures. Part 4: Silos and tanks." European Committee for Standardization, Brussels.

EN 1993-1-6 (2007). "Eurocode 3: Design of Steel Structures, Part 1-6: Strength and Stability of Shell Structures." Comité Européen de Normalisation, Brussels.

EN 1993-4-1 (2007). "Eurocode 3: Design of Steel Structures, Part 4-1: Silos.” Comité Européen de Normalisation, Brussels.

Gale B.R., Hoadley P.J. \& Schmidt L.C. (1986). "Aspects of Eccentric Discharge of Granular Material from a Circular Silo." Proc. of the 2nd Int. Conf. on Bulk Materials Storage, Handling and Transportation, IEAustralia, Wollongong, 258-263.

Gould, P.L. (1988) “Cylindrical Shell Slice-Beam”, Journal of Engineering Mechanics, American Society of Civil Engineers, Vol 114, No 5, May 1988, pp 905-911. 
Published in: Thin-Walled Structures, 61, 169-179.

DOI: http://dx.doi.org/10.1016/j.tws.2012.03.021

Greiner, R. (1981) "Buckling of cylindrical shells with stepped wall-thickness under wind load”. (in German), Der Stahlbau, 50, No. 6, pp. 176-179.

Greiner, R. and Derler, P. (1995) "Effect of imperfection on wind-loaded cylindrical shells", Thin Walled Structures, Vol 23, pp 271-281.

Hoff, N.J., Chao, C.C. and Madsen, W.A. (1964) "Buckling of a Thin-Walled Circular Cylindrical Shell Heated Along an Axial Strip", J. Appl. Mech., Vol. 31, Trans. ASME, Series E, June, pp 253-258.

NASA SP-8007 (1968) "Buckling of Thin-Walled Circular Cylinders", NASA Space Vehicle Design Criteria, National Aeronautics and Space Administration, Special Publication 8007, Langley, Virginia.

Nielsen J. \& Kristiansen N.O. (1980). "Related measurements of pressure conditions in full-scale barley silo and in model silo." Proc. Int. Conf. on Design of Silos for Strength and Flow, Lancaster, UK, 1-23.

Ross, B., Mayers, J. and Jaworski, A. (1965) "Buckling of Thin Cylindrical Shells Heated Along an Axial Strip", Experimental Mechanics, 5(8), pp 247-256.

Rotter J.M. (1986). "The analysis of steel bins subject to eccentric discharge." Proc. of the 2nd Int. Conf. on Bulk Materials Storage, Handling and Transportation, IEAustralia, Wollongong, 264-271.

Rotter, J.M. (2001) "Pressures, Stresses and Buckling in Metal Silos containing Eccentrically Discharging Solids", Festschrift Richard Greiner, Celebration volume for the 60th birthday of Prof. Richard Greiner, TU Graz, Austria, October pp 85-104.

Rotter, J.M. (2004) "Buckling of cylindrical shells under axial compression", in Buckling of Thin Metal Shells, eds J.G. Teng \& J.M. Rotter, Spon, London, pp 42-87. 
Published in: Thin-Walled Structures, 61, 169-179.

DOI: http://dx.doi.org/10.1016/j.tws.2012.03.021

Rotter, J.M. (2008) "Silo and hopper design for strength", Chapter 3 in Bulk Solids Handling- Equipment Selection and Operation, Ed D. McGlinchey, Blackwell, Oxford, pp 99-134.

Rotter, J.M. (2011a) "Silos and Tanks", Section 7.3 in Fifty Years of Progress for Shell and Spatial Structures, eds Ihsan Mungan and John Abel, 50 ${ }^{\text {th }}$ Anniversary of the International Association for Shell and Spatial Structures, IASS, pp 195-212.

Rotter, J.M. (2011b) "The New Framework for Shell Buckling Design and the European Shell Buckling Recommendations 5th Edition”, Journal of Pressure Vessel Technology, Vol. 133, Issue 1, February, pp. 011203-1 to 9.

Rotter, J.M. (2011c) "Shell buckling design and assessment and the LBA-MNA methodology", Stahlbau, Vol. 80, Heft 11, Nov., pp 791-803.

Rotter J.M. \& Teng, J.G. (1989). "Elastic stability of cylindrical shells with weld depressions.” Jrnl. of Struct. Eng., ASCE, 115(5), 1244-1263.

Rotter, J.M., Jumikis, P.T., Fleming, S.P. and Porter, S.J. (1989) "Experiments on the Buckling of Thin-Walled Model Silo Structures", Journal of Constructional Steel Research, Vol. 13, No. 4, 1989, pp 271-299.

Rotter, J.M., Cai, M. and Holst, J.M.F.G. (2011) "Buckling of thin cylindrical shells under locally elevated axial compression stresses", Journal of Pressure Vessel Technology, Vol. 133, Issue 1, February, pp. 011204-1 to 11.

Sadowski A. J. (2010). "Modelling of failures in thin-walled metal silos under eccentric discharge" PhD Thesis, The University of Edinburgh.

Sadowski A.J. \& Rotter J.M. (2010). "A Study of Buckling in Steel Silos under Eccentric Discharge Flows of Stored Solids.” Jrnl. of Eng. Mech., ASCE, 136(6), 769776. 
Published in: Thin-Walled Structures, 61, 169-179.

DOI: http://dx.doi.org/10.1016/j.tws.2012.03.021

Sadowski A.J. \& Rotter J.M. (2011a). "Buckling of very slender metal silos under eccentric discharge.” Engineering Structures, 33(4), 1187-1194.

Sadowski A.J. \& Rotter J.M. (2011b). "Steel silos with different aspect ratios: II behaviour under eccentric discharge." Journal of Constructional Steel Research, 67(10), 1545-1553.

Song C.Y. \& Teng J.G. (2003). "Buckling of circular steel silos subject to codespecific eccentric discharge pressures.” Engineering Structures, 25, 1397-1417.

Song C.Y., Teng J.G. \& Rotter J.M. (2004). "Imperfection sensitivity of thin elastic cylindrical shells subject to partial axial compression." Int. J. of Solids and Structures, 41, 7155-7180.

Teng J.G., Lin X. \& Rotter J.M. (2005). "Analysis of geometric imperfections in fullscale welded silos.” Engineering Structures, 27(6), 938-950. 